Review Article

\title{
Plasma Protein Carbonyls as Biomarkers of Oxidative Stress in Chronic Kidney Disease, Dialysis, and Transplantation
}

\author{
Graziano Colombo, ${ }^{1}$ Francesco Reggiani, ${ }^{2}$ Claudio Angelini, ${ }^{2}$ Silvia Finazzi, ${ }^{2}$ \\ Emanuela Astori, ${ }^{1}$ Maria L. Garavaglia, ${ }^{1}$ Lucia Landoni, ${ }^{1}$ Nicola M. Portinaro, ${ }^{3}$ \\ Daniela Giustarini $\left({ }^{D},{ }^{4}\right.$ Ranieri Rossi, ${ }^{4}$ Annalisa Santucci, ${ }^{1}$ Aldo Milzani, ${ }^{1}$ \\ Salvatore Badalamenti, ${ }^{2}$ and Isabella Dalle-Donne $\mathbb{i D}^{1}$ \\ ${ }^{1}$ Department of Biosciences (Department of Excellence 2018-2022), Università degli Studi di Milano, Milan I-20133, Italy \\ ${ }^{2}$ Humanitas Clinical and Research Center-Nephrology Unit, Rozzano I-20089, Italy \\ ${ }^{3}$ Dipartimento di Biotecnologie Mediche e Medicina Traslazionale, Università degli Studi di Milano, Rozzano I-20089, Italy \\ ${ }^{4}$ Department of Biotechnology, Chemistry and Pharmacy (Department of Excellence 2018-2022), University of Siena, \\ Siena I-53100, Italy
}

Correspondence should be addressed to Isabella Dalle-Donne; isabella.dalledonne@unimi.it

Received 27 May 2020; Revised 3 October 2020; Accepted 13 October 2020; Published 24 November 2020

Academic Editor: Stefanos Roumeliotis

\begin{abstract}
Copyright (C) 2020 Graziano Colombo et al. This is an open access article distributed under the Creative Commons Attribution License, which permits unrestricted use, distribution, and reproduction in any medium, provided the original work is properly cited.
\end{abstract}

\begin{abstract}
Accumulating evidence indicates that oxidative stress plays a role in the pathophysiology of chronic kidney disease (CKD) and its progression; during renal replacement therapy, oxidative stress-derived oxidative damage also contributes to the development of CKD systemic complications, such as cardiovascular disease, hypertension, atherosclerosis, inflammation, anaemia, and impaired host defence. The main mechanism underlying these events is the retention of uremic toxins, which act as a substrate for oxidative processes and elicit the activation of inflammatory pathways targeting endothelial and immune cells. Due to the growing worldwide spread of CKD, there is an overwhelming need to find oxidative damage biomarkers that are easy to measure in biological fluids of subjects with CKD and patients undergoing renal replacement therapy (haemodialysis, peritoneal dialysis, and kidney transplantation), in order to overcome limitations of invasive monitoring of CKD progression. Several studies investigated biomarkers of protein oxidative damage in $\mathrm{CKD}$, including plasma protein carbonyls (PCO), the most frequently used biomarker of protein damage. This review provides an up-to-date overview on advances concerning the correlation between plasma protein carbonylation in CKD progression (from stage 1 to stage 5) and the possibility that haemodialysis, peritoneal dialysis, and kidney transplantation improve plasma PCO levels. Despite the fact that the role of plasma PCO in CKD is often underestimated in clinical practice, emerging evidence highlights that plasma PCO can serve as good biomarkers of oxidative stress in CKD and substitutive therapies. Whether plasma PCO levels merely serve as biomarkers of CKD-related oxidative stress or whether they are associated with the pathogenesis of CKD complications deserves further evaluation.
\end{abstract}

\section{Introduction}

Chronic kidney disease (CKD) has a worldwide prevalence of around $8-16 \%$, and it is declared by the World Health Organization (WHO) as an ever-increasing public health problem [1]. CKD is usually characterized by albuminuria and/or decreased glomerular filtration rate (GFR), which is the volume of plasma filtered by the glomeruli per unit of time. A five-stage classification system for CKD has been established by the Kidney Disease Improving Global Outcomes (KDIGO) (Figure 1) [2]. Patients with stage 1-3 CKD are frequently asymptomatic. In CKD stages 1 and 2, GFR may be 


\begin{tabular}{|c|c|c|c|c|c|}
\hline \multicolumn{6}{|c|}{ Chronic kidney disease } \\
\hline Stage 1 & Stage 2 & Stage 3 & Stage 4 & Stage 5 & \multirow{4}{*}{$\begin{array}{l}\text { - Haemodialysis (HD) } \\
\text { - Peritoneal dialysis (PD) } \\
\text { - Kidney transplantation (KT) }\end{array}$} \\
\hline \multicolumn{5}{|c|}{ Kidney function } & \\
\hline $\begin{array}{l}\text { Normal } \\
\text { or high }\end{array}$ & $\begin{array}{l}\text { Mildly } \\
\text { decreased }\end{array}$ & $\begin{array}{l}\text { Mildly } \\
\text { to severely } \\
\text { decreased }\end{array}$ & $\begin{array}{l}\text { Severely } \\
\text { decreased }\end{array}$ & $\begin{array}{l}\text { Kidney failure } \\
\text { (ESRD) }\end{array}$ & \\
\hline 130 & 90 GFR, mL & $\begin{array}{l}60 \\
n / 1.73 \mathrm{~m}^{2} \mathrm{bo}\end{array}$ & rface area ${ }^{15}$ & 0 & \\
\hline
\end{tabular}

FIgURE 1: Five-stage classification system for CKD. During the progression of CKD, the decrease in kidney function, evaluated by the glomerular filtration rate (GFR), leads to a variety of disturbances in body homeostasis. The accumulation of uremic toxins, the increase in signs of volume overload, the worsening of hypertension, and the induction of metabolic and hormonal disturbances are typical of CKD patients. The progression of CKD often leads to a decline in residual renal function (RRF), eventually leading to renal replacement therapy (i.e., haemodialysis, peritoneal dialysis, and kidney transplantation).

normal or borderline normal; hence, reduced GFR alone does not clinch the diagnosis. Other elements due to tubular disorders, such as albuminuria, the presence of a pathological urine sediment, electrolyte unbalance, or histologic and structural abnormalities detected by imaging, can be useful to establish the diagnosis of CKD stages 1 and 2 [2]. Clinical manifestations from low kidney function typically appear in stages 4 and 5. Patients with CKD show a progressive decline in kidney function, and they develop end-stage renal disease (ESRD, i.e., CKD stage 5), where renal replacement therapy (RRT) is needed to ensure ESRD patient survival. RRT is achieved by haemodialysis (HD), peritoneal dialysis (PD), and/or kidney transplantation (KT). Compared to the general population, CKD patients have a higher risk of premature death, primarily because of cardiovascular diseases (CVDs) $[3,4]$. Traditional risk factors (such as age, diabetes, left ventricular hypertrophy, dyslipidemia, and hypertension) are predictive of CVD mortality in CKD patients [5]. In addition, CVD can also arise from nontraditional risk factors, including inflammation and oxidative stress, which are highly prevalent in CKD patients $[4,6-9]$.

Inflammation and oxidative stress interplay in a selfperpetuating vicious circle and drive $\mathrm{CKD}$ progression, $\mathrm{CVD}$, and other numerous complications such as malnutrition, atherosclerosis, coronary artery calcification, heart failure, anaemia, and mineral and bone disorders [10-13]. In fact, patients with CKD typically suffer from chronic inflammation and have severely impaired antioxidant systems, which worsen gradually with the progression of renal failure [10]. Inflammation is characterized by an increase in inflammatory markers, including cytokines (such as interleukin-6, interleukin-1, tumour necrosis factor- $\alpha$, and adipokines), acute phase proteins (mainly C-reactive protein), and adhesion molecules, which are associated with many complications during $\mathrm{CKD}$, as clinical studies have demonstrated [11]. Many factors contribute to chronic inflammation in $\mathrm{CKD}$, including the increased production of proinflammatory cytokines, oxidative stress, acidosis, chronic and recurrent infections, intestinal dysbiosis, and altered adipose tissue metabolism [12]. Inflammation contributes to the progression of $\mathrm{CKD}$, oxidative stress, insulin resistance, endothelial dysfunction, mineral and bone disease, anaemia, and resistance to erythropoietin [11]. High levels of oxidative stress have been found in the early stages of CKD, which increase in parallel with the progression to ESRD [13] and even more in patients undergoing HD [14, 15]. In particular, HD induces inflammation and oxidative stress due to loss of antioxidants during the dialysis session and activation of white blood cells, which generate ROS [16]. Compared to $\mathrm{HD}, \mathrm{PD}$ is a more biocompatible dialysis modality that induces a lower level of oxidative stress, mainly due to the composition of $\mathrm{PD}$ solutions (low $\mathrm{pH}$, high lactate content, increased osmolarity, high glucose concentration, and related degradation products) $[17,18]$. In particular, HD induces inflammation and oxidative stress due to loss of antioxidants during the dialysis session and activation of white blood cells, which generate ROS [19]. Compared to HD, PD is a more biocompatible dialysis modality that induces a lower level of oxidative stress, mainly due to the composition of PD solutions (low $\mathrm{pH}$, high lactate content, increased osmolarity, high glucose concentration and related degradation products) $[20,21]$.

Oxidative stress has also been associated with the production of highly reactive intermediates during inflammation; ROS, for their part, further enhance the inflammatory response by triggering proinflammatory mediators. In the kidneys, ROS are mainly produced by the mitochondrial respiratory chain and by the different isoforms of the enzyme NADPH oxidase. Oxidative stress is responsible for progressive renal damage, which can lead to renal ischemia, lesions to the glomeruli, cell death, and apoptosis, exacerbating the severe inflammatory processes. Further, oxidative stress is also responsible for several risk factors for $\mathrm{CKD}$, such as diabetes, hypertension, and atherosclerosis [11]. Several biomarkers of oxidative stress, such as malondialdehyde, oxidized low-density lipoprotein, advanced glycation end products, and 7,8-dihydro-8-oxo-2'-deoxyguanosine, have increased levels in patients with CKD [11]. However, their specificity as a biomarker of oxidative stress can be questionable, as in the case of oxidized low-density lipoprotein, which is most commonly measured in plasma or isolated lipoprotein by immunological methods using one of three different antibodies, each of which has methodological limitations [22]. All methods available for the detection of malondialdehyde show pitfalls, including the numerous commercial kits 
that lack specificity, making their significance for clinical practice dubious [22]. The thiobarbituric acid reactive substance assay to detect malondialdehyde reveals reproducibility and reliability when combined with HPLC, although it requires individual sample processing and its validity as a biomarker of in vivo oxidative stress remains uncertain, making it less suitable for routine clinical use [22].

$\mathrm{CKD}$ is also characterized by the accumulation of uremic toxins released from the intestinal tract, which have become clinically relevant in CKD progression and are tightly related to many CKD-associated systemic complications, including inflammation, oxidative stress, and decreased production of nitric oxide by endothelial cells [23]. The proinflammatory state, the enhanced oxidative stress, and the accumulation of uremic toxins also cause endothelial damage. Under uremia, endothelial cells produce danger-associated molecular patterns (molecules released by stressed, damaged, or necrotic cells that act as endogenous danger signals to promote and perpetuate a noninfectious inflammatory response), which induce the expression of adhesion molecules, the production of proinflammatory cytokines, and an enhanced production of ROS in endothelial cells [24]. Uremic toxins are involved in the inflammatory state in CKD and contribute to many uremia-associated dysfunctions [11]. In fact, several studies have shown that uremic toxins increase the levels of TNF- $\alpha$ and IL- 6 and cause an exacerbation of the inflammatory state through the increase in ROS production [11].

Protein carbonyls (PCO) are among the most successful biomarkers of oxidative stress and are associated with disease state and treatment in multiple illnesses [22, 25-28]. The easy sampling of plasma proteins and the relatively long half-life of many of them make plasma PCO an attractive biomarker of oxidative stress in CKD $[29,30]$. The most commonly used methods for quantifying PCO rely on derivatization with 2,4dinitrophenylhydrazine (DNPH), which specifically reacts with PCO associated with aldehydes and ketones but does not react with other carbonyl-containing functional groups such as carboxylic acids and esters. DNPH generates the stable 2,4-dinitrophenylhydrazone (DNP) adduct (Figure 2) that absorbs UV light; therefore, PCO can be detected by a spectrophotometric assay [31]. DNPH-derivatized PCO can also be detected by specific anti-DNP antibodies by enzyme-linked immunosorbent assay (ELISA) and Western blot. The ELISA makes use of biotin-linked anti-DNP antibodies that bind DNP-derivatized proteins and allow detection with streptavidin-HRP [32, 33]. Carbonylation of specific plasma proteins is often detected by Western blot. After derivatization with DNPH, plasma proteins are separated by one-dimensional sodium dodecyl sulphate polyacrylamide gel electrophoresis (1D SDS-PAGE) or by twodimensional gel electrophoresis (2D-GE), electrotransferred from the gel to a polyvinylidene fluoride (PVDF) membrane, and then, PCO can be immunodetected using primary antiDNP antibodies and horseradish peroxidase- (HRP-) conjugated secondary antibodies [34, 35]. For mass spectrometry (MS) analysis, protein bands (or spots) can be excised from the gel, in-gel reduced, thiol-alkylated, digested with trypsin, and identified by matrix-assisted laser desorption/ionization time-of-flight (MALDI-TOF)/MS mass fingerprinting [3638]. PCO can also be detected by fluoresceinamine, a molecule that, unlike DNPH, labels PCO derived from metalcatalysed oxidative modification. Climent and colleagues demonstrated that fluoresceinamine labels specifically the $\gamma$-glutamyl semialdehyde group [39].

In this review, we summarize and discuss the main studies that have assessed plasma PCO levels in CKD, dialysis, and kidney transplantation and the potential role of protein carbonylation in driving CKD progression.

\section{Plasma Protein Carbonyls in CKD}

Although a high prevalence of oxidative stress in CKD is now well-established $[4,6,30]$, few studies measured biomarkers of oxidative stress in people with CKD. Increased oxidative stress in patients with CKD stage 3 or higher, including ESRD, is demonstrated by an increase in plasma protein thiol oxidation, PCO, advanced oxidation protein products (AOPPs), and protein-bound di-tyrosines ([40-42] and citations therein). However, the properties of the oxidative modifications, e.g., the transience of cysteine modifications, their low abundance, e.g., protein-bound di-tyrosines, or methodological issues concerning the reproducibility, accuracy, and reliability of their detection, e.g., AOPPs, limit their applicability in clinical practice. Considering that PCO are chemically stable, their concentration is often higher than that of other biomarkers (since PCO formation can derive from different mechanisms), and validated detection methods are available $[22,34,43]$, the plasma PCO assay has some advantages over other methods to assess oxidative stress and protein oxidative damage in clinical practice. In particular, the methods that seem to be most applicable in clinical settings are ELISA, as commercial kits are available, and HPLC, both of which allow for the rapid processing of many samples, the use of internal/external standards, and comparison of samples under constant conditions [22].

Eight studies examined the plasma PCO level in patients with CKD at various stages by spectrophotometric assay and ELISA (Table 1). Carbonylation of individual plasma proteins was measured by Western blot only in one study [44]. Four out of eight studies examined plasma PCO levels in patients with CKD compared with healthy subjects [45-47], while the other four examined plasma PCO levels in CKD patients at various stages [48-51].

Oberg et al. [45] compared 60 adult/elderly patients with CKD stages 3-5 (67 \pm 14 years, 29 of whom with diabetes mellitus) and healthy control subjects $(51.4 \pm 1.7$ years) (Table 1), showing that plasma PCO levels were significantly higher in patients with CKD than in healthy control subjects, as subsequently confirmed by other studies $[46,48]$. As no significant correlation between GFR and plasma PCO content was observed [45], the authors suggested that PCO can undergo renal clearance primarily via renal tubular metabolism rather than glomerular filtration; plasma PCO content could therefore be largely regulated by proximal tubular function [45].

The plasma PCO level increased in parallel with decreased renal function (measured as creatinine clearance) 


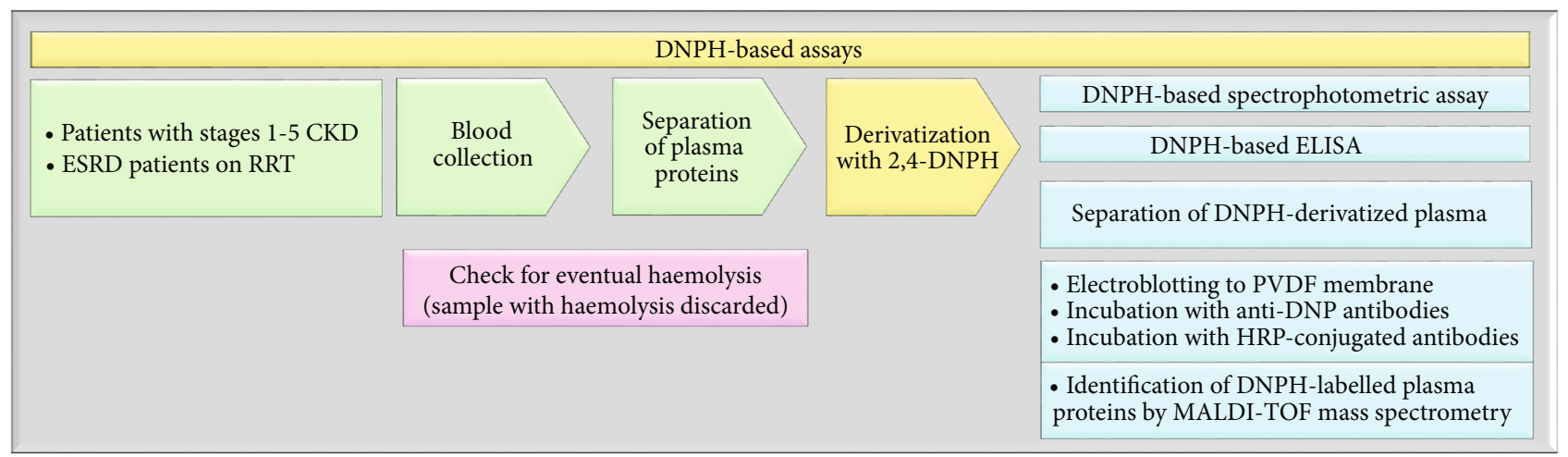

FIgure 2: DNPH-based assays for PCO detection. Assays for the detection of PCO involve the derivatization with 2,4-DNPH, leading to the formation of a stable dinitrophenylhydrazone product. PVDF: polyvinylidene fluoride membrane; HRP: horseradish peroxidase; MALDITOF: matrix-assisted laser desorption/ionization time-of-flight; RRT: renal replacement therapy.

$(R=-0.692, p<0.0001)$ in elderly patients $(60.9 \pm 15.2$ years) with CKD at stages 1-5 [48]; in addition, a significantly positive correlation was observed between plasma PCO and blood urea nitrogen (BUN) $(R=0.695, p<0.0001)$ [48]. Evaluation of plasma protein carbonylation in elderly patients with CKD at stages 1-4 showed that the PCO level in patients classified at stage 4 was higher than that of patients at stages 3,2 , and $1(p<0.001)$ [50]. A further study conducted in elderly patients with CKD stages 2-5 highlighted that plasma levels of PCO in CKD stage 5 were significantly higher than in stage $2(p=0.003)$, stage 3 $(p=0.015)$, and stage $4(p=0.011)$ [49]. On the contrary, the plasma PCO level in young patients (aged from 1.4 to 18.6 years) with CKD stages 1-5 did not depend on the degree of renal failure [51], probably as a consequence of the different diseases underlying kidney dysfunction in young people compared to the elderly. In fact, CKD is more commonly caused by diabetes mellitus and long-lasting hypertension in the elderly, while it is prevalently due to congenital abnormalities of the kidneys and urinary tract in young patients [51]. One study found significantly higher plasma PCO levels in CKD patients, both on conservative therapy (CT) and HD, than in healthy control adults [47]. This study also showed a negative correlation between plasma PCO levels and creatinine clearance [47] that was confirmed [49] or not [45] by other studies.

The plasma PCO level has been shown to have a negative correlation with GFR $(R=-0.26, p<0.05)$ and a positive correlation with C-reactive protein (CRP) $(R=0.49, p<$ $0.0001)$ and fibrinogen $(R=0.30, p<0.01)$ levels [49]. Assessment of carbonylation of plasma albumin in elderly patients with CKD stages 2-5 and healthy control subjects by $1 \mathrm{D}$ Western blot analysis showed increasing carbonylation of albumin in parallel with the severity of CKD, which reached statistical significance at CKD stages 3 and 4 ( $p<0.01$, compared to healthy control subjects) [44].

\section{Plasma Protein Carbonyls in Haemodialysis (HD)}

Patients receiving $\mathrm{HD}$, the most common type of dialysis, show a high prevalence of inflammation and oxidative stress
$[11,13,14,52]$ and are exposed to additional health risk factors determined by the procedure itself (e.g., rapid changes in plasma electrolyte levels, haemodynamic stresses because of intra- and interdialytic changes in cardiac filling, and fluctuations of blood pressure). Inflammatory response can be caused by the use of synthetic membranes during HD [53] as well as by dialysate impurities, as biomarkers of inflammation and oxidative stress appear significantly lower in patients treated with ultrapure versus standard dialysate [54]. Various mechanisms have been proposed to account for the additional oxidative stress observed in patients following $\mathrm{HD}$, including the activation of neutrophil NADPH oxidase, which provokes inflammation with the release of reactive oxygen species (ROS) $[14,55]$, and the depletion of circulating low-molecular-weight dialyzable antioxidants [56]. Some typical complications in patients undergoing HD can further exacerbate oxidative stress. For example, anaemia is a frequent and early complication of CKD and the treatment with iron can increase oxidative stress levels. Anaemia prevalence increases with worsening of renal function, involving over $50 \%$ of patients at stage 4 and virtually almost $100 \%$ of patients receiving HD [57]. Erythropoiesis is limited by the low iron availability [58], deriving from either absolute or functional deficiency and from the iron block due to underlying inflammatory status [59]. Iron deficiency is common in patients with ESRD on HD [60] overall; they lose on average 1-2 $\mathrm{g}$ of iron per year, and some of them as much as 4 to $5 \mathrm{~g}$ per year [61]. In the absence of concomitant iron supplementation, erythropoietin therapy does not affect oxidative stress [62]. Nevertheless, intravenous iron supplementation is one of the most used interventions in patients with CKD to correct anaemia [63], even if it further aggravates oxidative stress [64]. Recently, iron overload has been shown to increase plasma PCO levels in ESRD patients on HD [65]. Moreover, plasma PCO were positively associated with ferritin level $(R=0.35, p=0.01)$ [65].

Biomarkers of inflammation are elevated in ESRD patients on HD [66-69]. The level of CRP increases in 30$60 \%$ of patients receiving $\mathrm{HD}$, and it is closely associated with the progression of atherosclerosis, cardiovascular morbidity, and mortality [70]. Biomarkers of oxidative stress, such as $S$-thiolated proteins [71-73] and protein-bound di- 


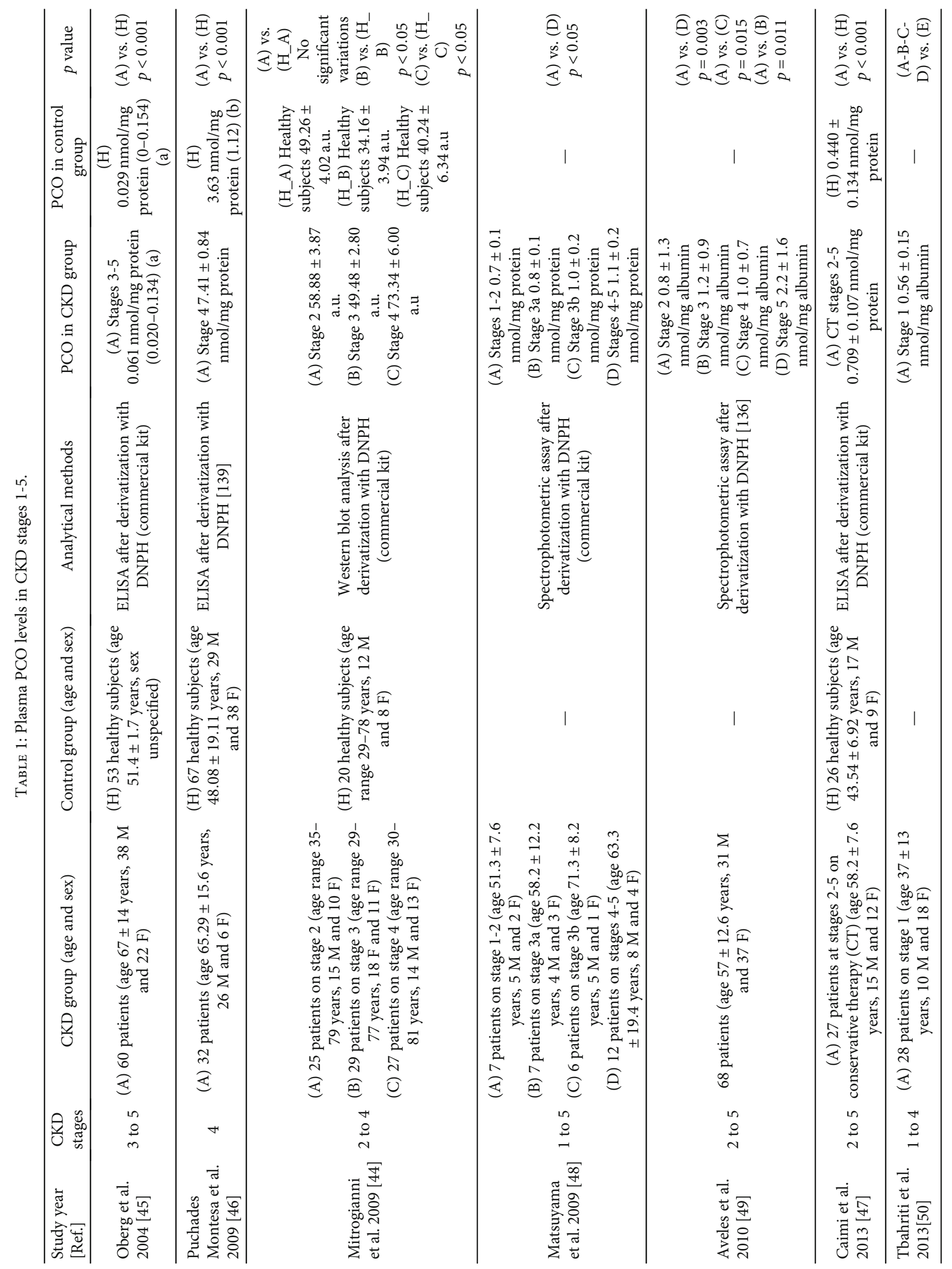




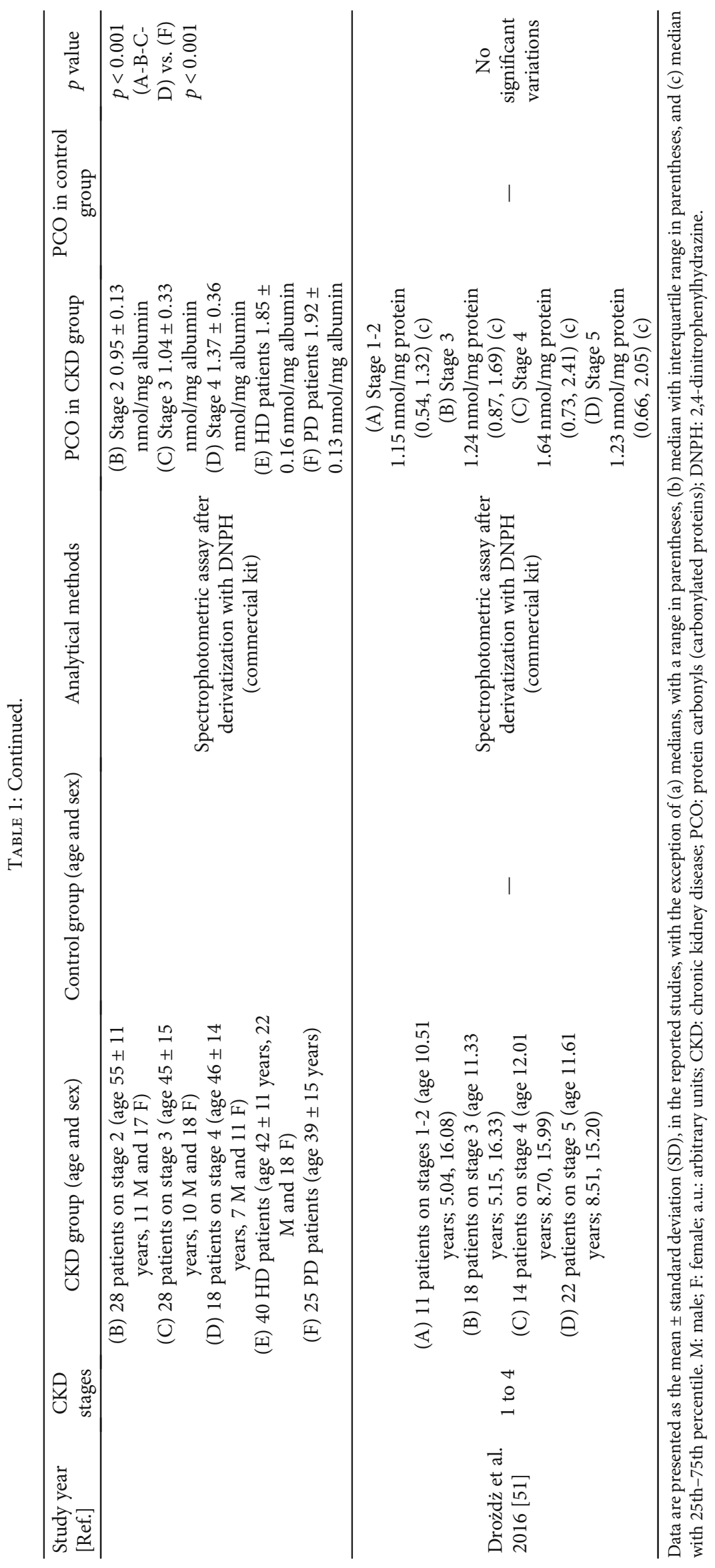




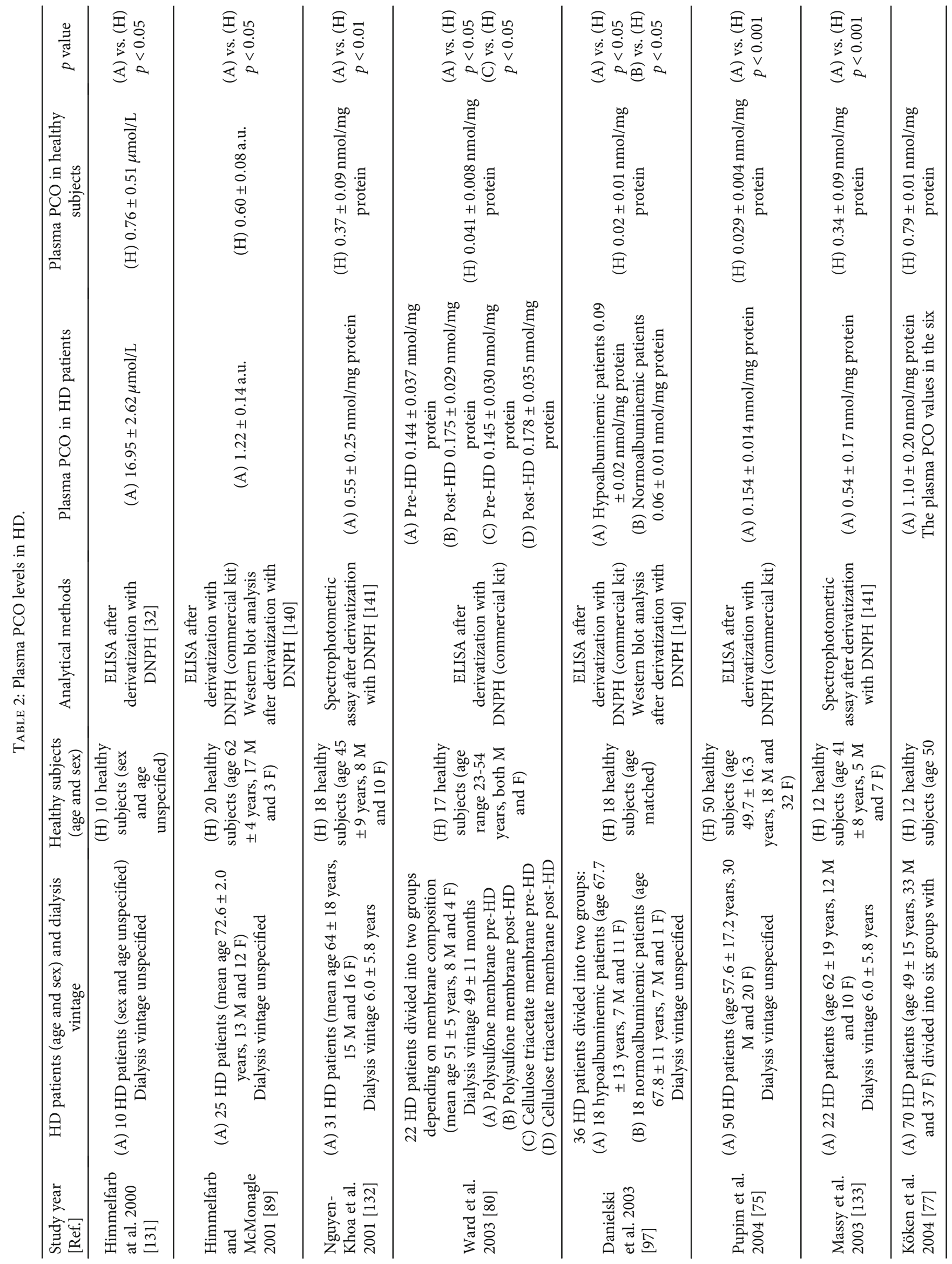




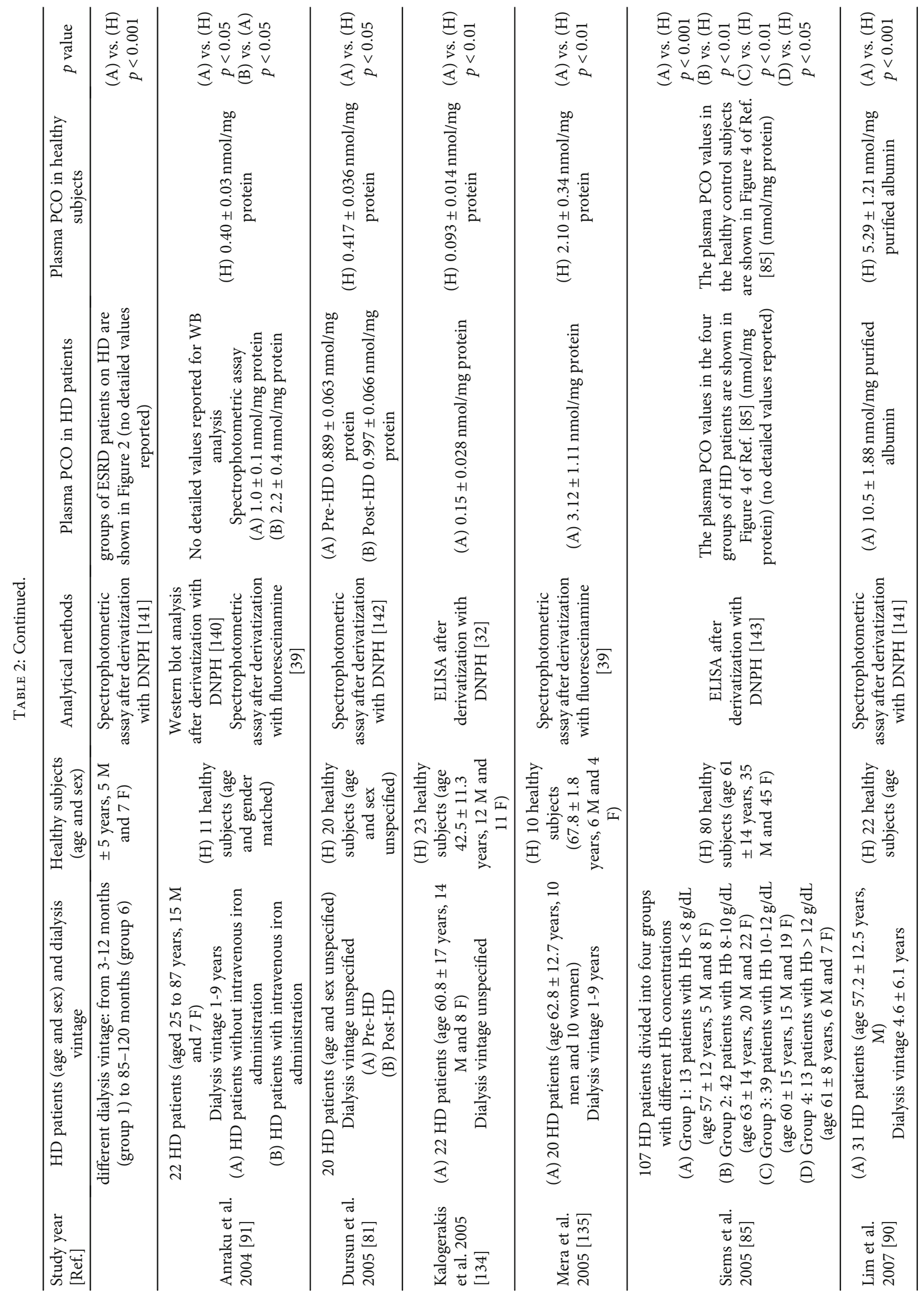




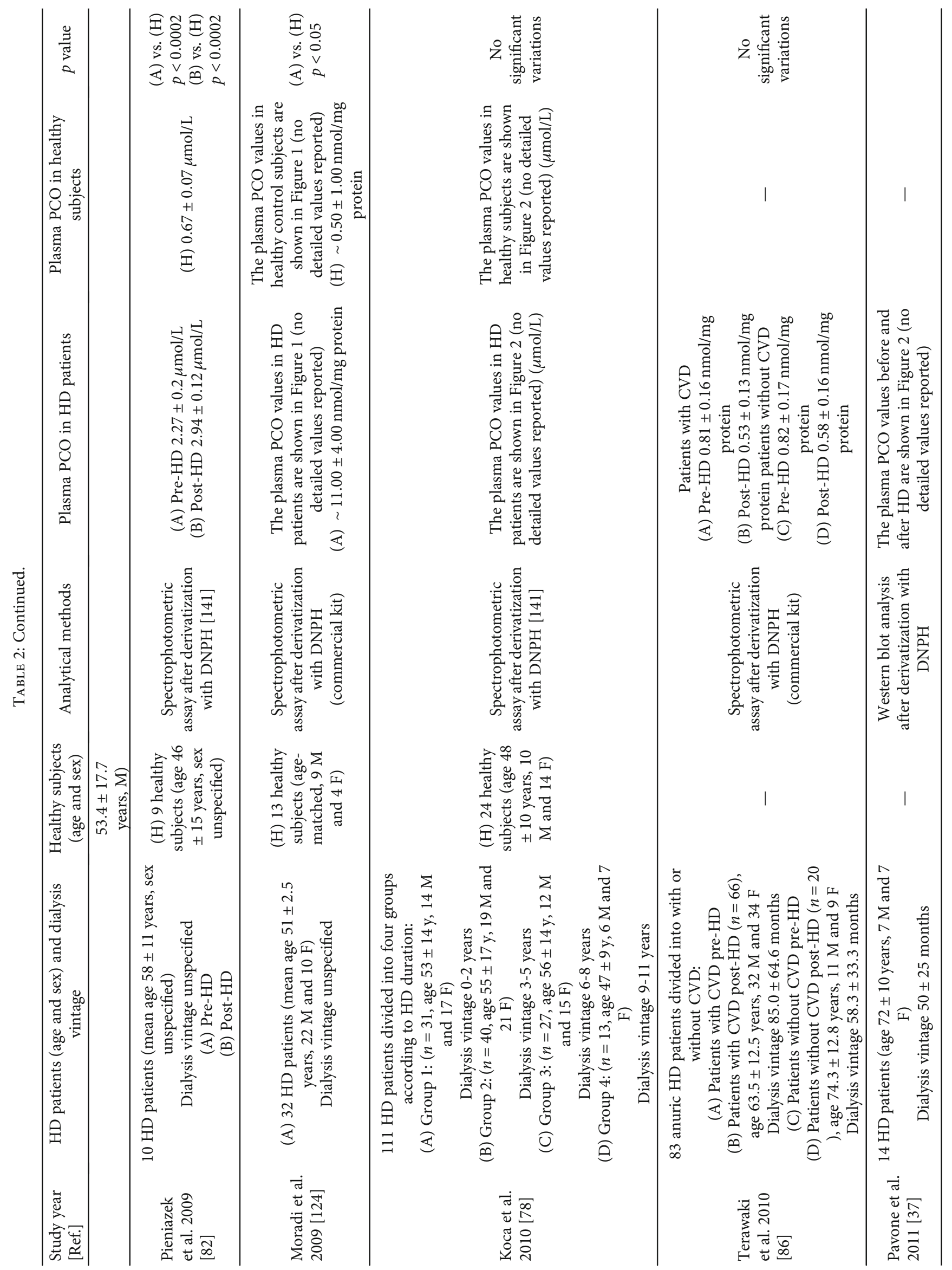




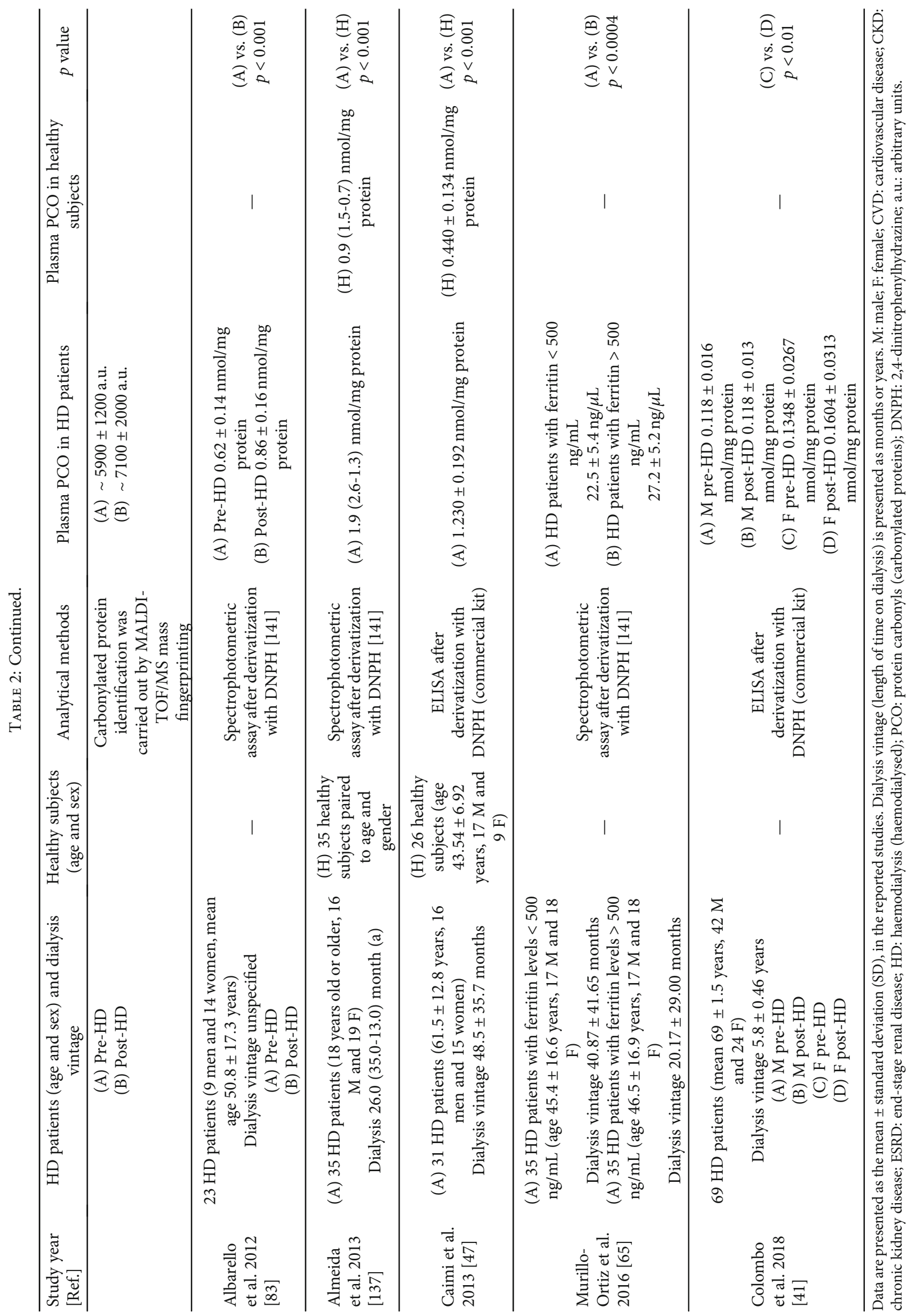


tyrosines $[40,74]$, are also heightened in these patients. Additionally, 24 studies measured plasma PCO levels in ESRD patients on HD (Table 2), 18 of which determined that plasma PCO levels in haemodialysed patients are higher than in healthy subjects (Table 2).

Colombo et al. [74] were the first to point out significant differences in plasma PCO levels between healthy subjects and ESRD patients on HD. Many other studies later confirmed those findings (Table 2). Interestingly, Caimi et al. [47] also showed that patients receiving $\mathrm{HD}$ had higher plasma PCO levels not only when compared with healthy control subjects but also in comparison with CKD patients on CT.

A prospective cohort study (12-month period) showed that, at baseline, plasma PCO levels were significantly higher in patients with ESRD before starting the HD therapy than in healthy subjects [75]. After the initiation of $\mathrm{HD}$, there were no significant changes both in plasma PCO content and in plasma concentration of inflammatory biomarkers, which remained stable over a 12-month period [75]. Other studies conducted in ESRD patients on HD reported an increase in IL-6 levels during a 3-year follow-up period [76] and a positive correlation between plasma PCO levels (higher than in healthy subjects) and the duration of $\mathrm{HD}$ (3 to 120 months) $(R=0.364, p<0.01)$ [77]. Differently, another study showed that plasma PCO content was not significantly different in ESRD patients receiving $\mathrm{HD}$ for up to eleven years (Table 2) [78].

A study evaluated the within- and between-individual variability of plasma PCO levels in ESRD patients on HD, with PCO measurements every two weeks for ten weeks (six measures) [79]. Within-individual coefficients of variation (CVs) and between-individual CVs for PCO were, respectively, 16.3\% (range 8.4-29.5\%) and 19.5\% (range 15.6-24.5\%). PCO variability was not affected by various personal and external factors such as dietary antioxidant intake, medications, and clinical and demographic parameters. However, the higher number of males (10 men and 4 women) participating in the study may have influenced the ability to look at the effect of sex [79].

Some studies examined plasma PCO levels before (preHD) and after (post-HD) a single HD session (Table 2). Among these, Ward et al. [80] were the first to measure plasma PCO levels pre-HD and post-HD. They reported that plasma PCO levels increased slightly, but significantly over the course of dialysis [80]. Several other studies found that the post-HD plasma PCO content was higher than the preHD one [41, 47, 81-84]. Caimi et al. [84] detected increased levels of $\mathrm{PCO}$ in $\mathrm{CKD}$ patients on $\mathrm{HD}$ in comparison with normal controls before and, especially, after the HD session, but they did not find any difference in PCO after subdividing haemodialysed patients according to their dialysis vintage (i.e., length of time on dialysis) or the type of filter employed for HD. Interestingly, Colombo et al. [41] divided ESRD patients on HD into two groups according to sex, and they reported that pre-HD and post-HD plasma PCO levels in females were significantly different while in males were not. This finding suggests that female ESRD patients may be more susceptible to oxidative stress induced by the HD session than male ESRD patients [41]. As a consequence, the female sex could be considered a "risk factor" associated with HDinduced plasma protein carbonylation in ESRD patients. Two studies, on the other hand, reported that plasma PCO concentration did not change during the HD session [85] and that, in anuric haemodialysed patients with or without cardiovascular diseases, post-HD plasma PCO levels decreased [86]. However, it is not specified whether these differences are statistically significant [86].

In ESRD patients undergoing $\mathrm{HD}$ or $\mathrm{PD}$, serum albumin is considered a biomarker of nutritional status and inflammation and a predictor of mortality $[87,88]$. Some studies have shown that albumin is the major carbonylated protein in ESRD patients on HD (Table 2). In 2001, Himmelfarb and McMonagle [89] reported, for the first time, that the carbonylation of albumin accounts for almost all the excess plasma protein oxidation observed in haemodialysed patients when compared to healthy subjects. Later studies confirmed and reinforced this finding. The carbonyl content of purified albumin, detected by spectrophotometric analysis and immunoblot, was much higher in ESRD patients on HD than in healthy subjects [90]. Carbonylation of albumin increased in correlation with CKD stage severity, attaining significance at stages 3 and 4 ( $p<0.01$, compared to healthy controls), and reached even higher levels in patients undergoing HD [44]. As mentioned above, in haemodialysed patients, intravenous iron administration substantially increases carbonylation of plasma proteins [65], including albumin carbonylation [91]. Comparing healthy control subjects, ESRD patients undergoing HD without intravenous iron administration, and ESRD patients undergoing HD with intravenous iron administration, only albumin was found to be significantly carbonylated in haemodialysed patients, and intravenous iron administration increased the albumin carbonylation [91].

Advanced age ( $>65$ years) has been associated with hypoalbuminemia (serum albumin level $<3.8 \mathrm{~g} / \mathrm{dL}$ ) in two large cross-sectional studies $[92,93]$. Hypoalbuminemia in ESRD patients on HD is primarily associated with systemic inflammation [94] and confers a greater mortality risk [95, 96]. Danielski et al. [97] reported that both plasma PCO levels and albumin carbonyl content were significantly increased in normoalbuminemic and hypoalbuminemic ESRD patients on HD in comparison to healthy subjects, even if the difference between hypoalbuminemic and normoalbuminemic haemodialysed patients did not reach the statistical significance [97].

Albumin is not the only protein whose carbonylation increases in ESRD patients on HD [37]. Using Western blot with anti-DNP antibodies and MALDI-TOF/MS mass fingerprinting associated with nano-LC-MS/MS analysis, Pavone et al. [37] showed that post-HD plasma PCO levels were significantly increased compared to pre-HD levels and that carbonylation targets numerous plasma proteins. The same authors used MALDI-TOF/MS mass fingerprinting to identify carbonylated proteins in blood samples before and after the HD session carried out with ethylene vinyl alcohol and cellulose diacetate membranes. $\alpha 2$-Macroglobulin, chain A $\alpha 1$-antitrypsin, fibrinogen $\gamma$ chain, immunoglobulin $\gamma 1$, 
proapolipoprotein, transferrin, and albumin were found as the main carbonylated plasma proteins after HD [36].

\section{Plasma Protein Carbonyls in Peritoneal Dialysis (PD)}

PD is an alternative to HD and is used by approximately 200,000 ESRD patients worldwide, representing approximately $7 \%$ of the total dialysis population [98]. In PD, the peritoneal membrane acts as a dialyzing membrane. To achieve this, a dialysis solution (dialysate) is instilled in the peritoneal cavity through a peritoneal catheter. After a dwell time, the dialysate is drained out. How long the dialysate is present in the peritoneal cavity, how many times the dialysate is changed, and the duration of the dwell time depend on individual patient requirements. While the dialysate is present in the peritoneal cavity, across the peritoneal membrane there is a transport of solutes and water between the blood in the peritoneal capillaries and the dialysis solution, which is typically rendered hyperosmolar through the addition of glucose or other osmotic agents. Through this mechanism, the elimination of waste products and the correction of fluid and electrolyte imbalances are achieved [99]. Even though $\mathrm{HD}$ and $\mathrm{PD}$ can be viewed as equivalent therapies and used as primary therapy for ESRD patients [100], there are important differences between them. PD exposes patients daily to greater amounts of glucose loading, leading to a much higher prevalence of insulin resistance, dyslipidemia, and metabolic syndrome [101]. PD may also accelerate the development of atherosclerosis lesions through increased lipid oxidation and glycosylation [102]. Otherwise, patients with ESRD undergoing $\mathrm{HD}$ are exposed to a greater risk of CVDs because they show a more rapid decline of residual renal function (RRF) [103] and a more hyperdynamic status due to the arteriovenous fistula and the extracorporeal circulation [104]. Although PD is considered a less invasive therapy than HD, it produces chronic inflammation in the peritoneal cavity leading to an increased level of proinflammatory cytokines, which alters peritoneal membrane integrity [105]. Several lines of evidence indicated that oxidative metabolism in peripheral and peritoneal phagocytes is activated during PD with conventional dialysate, which is characterized by a high concentration of glucose, glucose degradation products, low $\mathrm{pH}$, and high osmolality [106]. Bioincompatibility of PD solutions also seems to play a central role in the oxidative stress increase [107].

Five studies compared plasma PCO levels in patients with ESRD undergoing PD or HD, while one study examined plasma PCO content in ESRD patients on PD and healthy individuals (Table 3). Erdoğan et al. [108] compared plasma PCO content of patients with ESRD undergoing HD or PD with that of healthy individuals, showing that plasma PCO levels in ESRD patients on HD or PD are similar to those of healthy controls. Otherwise, another study showed that plasma PCO levels in ESRD patients on PD were lower than in haemodialysed patients, maybe because HD is associated with higher protein oxidation or because patients undergoing PD had greater RRF [109]. Conversely, two more recent studies showed that plasma PCO levels were higher in ESRD patients undergoing PD than in those undergoing $\mathrm{HD}$ [50, 110 ], although in one of the two studies it is not clear whether differences were statistically significant [50]. Another investigation proved that, in ESRD patients on PD, there was a highly significant positive correlation between copper/zinc ratio, the levels of CRP, and plasma PCO levels [111], whereas copper/zinc ratio was negatively correlated with the percentages of $\mathrm{B}$ - and $\mathrm{T}$-lymphocytes and the ratio of CD4/CD8 antigens. Therefore, the authors suggested that, in ESRD patients on $\mathrm{PD}$, elevated copper/zinc ratios are associated with increased oxidative stress and inflammation [111].

Mitrogianni et al. [44] estimated the carbonylation of plasma albumin in ESRD patients undergoing HD or PD compared to healthy control subjects by Western blot, showing that albumin carbonylation was higher in ESRD patients on HD, while it did not differ in ESRD patients on PD compared to controls. They suggested that PD may be more biocompatible, avoiding the generation of excess oxidative burden. Lack of contact of the blood with the dialysis membranes and less usage of intravenous iron administration might explain, at least in part, the low levels of plasma PCO observed in ESRD patients undergoing PD. The quite important albumin losses in ESRD patients on $\mathrm{PD}$, replaced by newly synthesized albumin, may contribute to the lower albumin carbonylation [44].

\section{Plasma Protein Carbonyls in Kidney Transplantation (KT)}

$\mathrm{KT}$ is considered the best therapeutic option in ESRD, because it permits a higher quality of life compared to HD and PD. Moreover, KT presents the lowest mortality rates, around $1.5-7 \%$ per year [112]. In KT anaemia, in addition to hyperhomocysteinemia, it can induce oxidative stress [113]. Oxidative stress and inflammation can produce graft tissue damages because of fibrosis and nephron losses by necrosis or apoptosis [114].

Two studies examined plasma PCO levels before and after KT. A prospective cohort study evaluated timedependent changes in biomarkers of inflammation and oxidative stress (plasma PCO levels) in 19 patients (mean age $38.3 \pm 13.7$ years, 11 men and 8 women), comparing them to 50 healthy control subjects (mean age $48.2 \pm 16$ years, 18 men and 32 women) [115]. This study reported that patients had substantial improvements in inflammatory biomarkers and plasma PCO levels after the restoration of kidney function by transplantation. Plasma PCO levels decreased rapidly, with significant changes notable within the first postoperative week $(p<0.001)$; final posttransplant levels of plasma PCO in recipients were not statistically different from those of healthy subjects $(p<0.05)$. This study also showed that CRP levels decreased significantly from baseline within two months after renal transplantation $(p<0.001)$ [115]. The second study investigated plasma protein carbonylation in 21 patients (mean age $36 \pm 17$ years, men 50\%) who underwent a living donor KT and were evaluated before the transplantation and analyzed longitudinally after a mean follow-up time of nine months [35]. This study showed that 


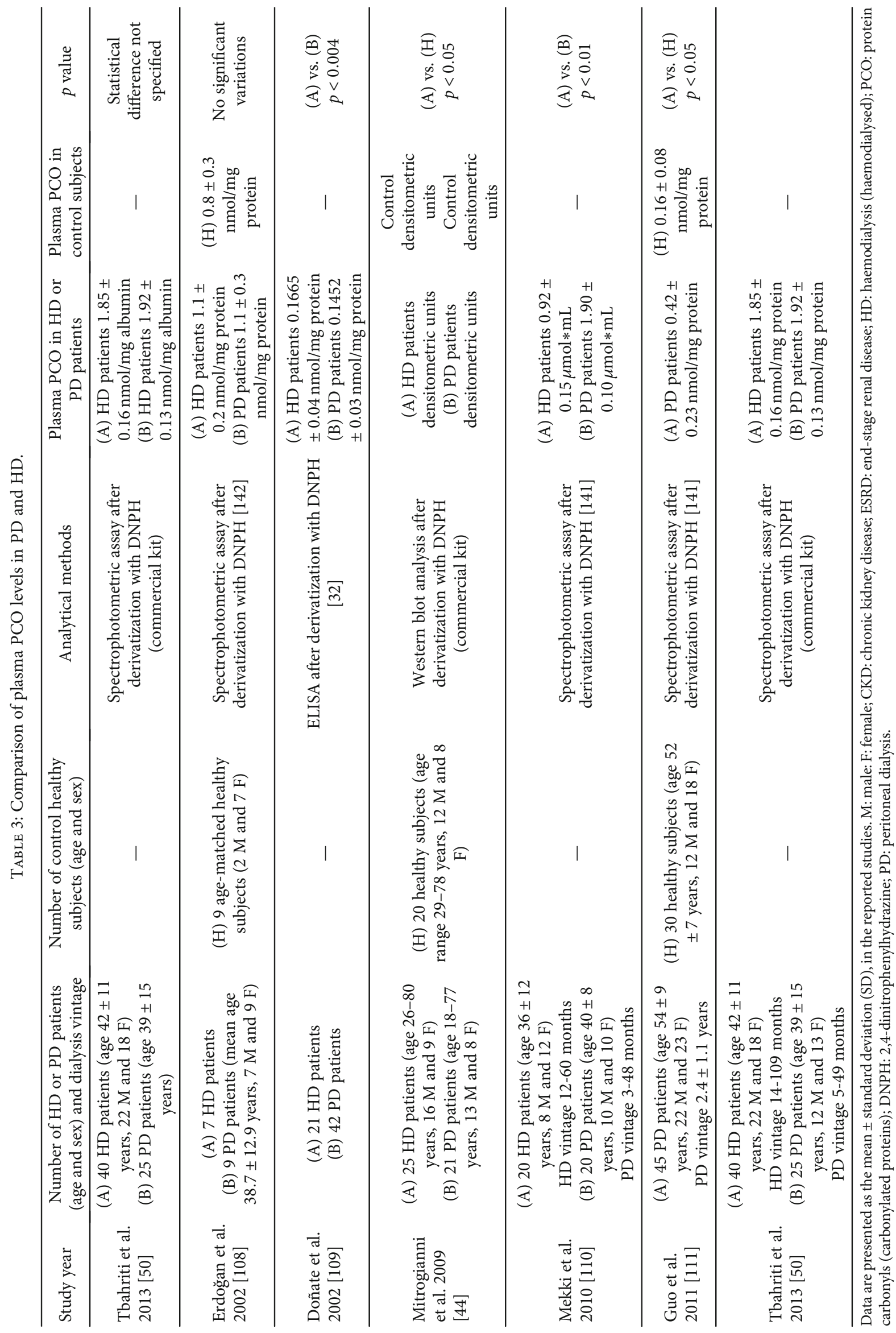


plasma PCO levels declined from seven to 11 months after KT. Plasma PCO content was significantly reduced after KT $(1.4 \pm 0.4 \mathrm{nmol} / \mathrm{mg}$ albumin) compared to pretransplantation $(2.0 \pm 1.4 \mathrm{nmol} / \mathrm{mg}$ albumin, $p<0.05)$. The study also revealed a significant correlation between CRP and plasma PCO levels after the transplantation $(R=0.65, p<0.005)$ [49].

\section{Conclusion and Perspectives}

Plasma PCO levels are quite heterogeneous both in CKD patients (Table 1), in patients on RRT (Tables 2 and 3), and in healthy control individuals (Tables 1-3). A cause of PCO variability could be the use of different methods to measure plasma PCO levels due to the lack of a reference method. Nevertheless, even when the same methodology was used, a critical emerging aspect is the high variability of measurements (Table 1). The absolute value of plasma PCO content measured by ELISA in control and CKD subjects seems to spread over two orders of magnitude (e.g., 0.029 and $0.061 \mathrm{nmol} / \mathrm{mg}$ protein [45], 0.440 and $0.709 \mathrm{nmol} / \mathrm{mg}$ protein [47], and 3.63 and $7.41 \mathrm{nmol} / \mathrm{mg}$ protein [46]). This variability needs to be reduced by standardizing references or procedures to make comparable data obtained at different times and laboratories. The aim is to give solidity as well as diagnostic and prognostic value to PCO, an established biomarker of oxidative stress.

A problem with the DNPH-based spectrophotometric assay may be that its results are frequently displayed in different units, e.g., nmol/mg protein, $\mathrm{nmol} / \mathrm{mg}$ albumin, $\mathrm{nmol} / \mathrm{L}$, $\mathrm{mmol} / \mathrm{L}, \mathrm{ng} / \mu \mathrm{L}$, and $\mu \mathrm{mol} * \mathrm{~mL}$ (Tables $1-3$ ), making them particularly difficult to compare between different studies. In addition, a limit of the DNPH-based spectrophotometric assay is that absorbance wavelengths of haemoglobin are similar to those of DNPH and this can interfere with DNPH measurement, leading to inaccurate estimation of plasma PCO levels [116]. Therefore, reproducible results can arise only from meticulous sample preparation (i.e., during plasma separation from red blood cells, haemolysis should be strictly avoided) (Figure 2).

RRF can further contribute to variability in plasma PCO levels among patients with ESRD undergoing dialysis. Moreover, in various studies, the inclusion/exclusion criteria of CKD patients are quite heterogeneous or even unspecified (Table 4-Supplementary Material). Moreover, age, sex, ethnicity, and lifestyle can also potentially result in PCO variability. Therefore, the preliminary results of these small studies should be confirmed in the future with a larger number of CKD patients and/or patients on RRT with homogeneous (or at least well-specified) inclusion/exclusion criteria and healthy control subjects with different demographic characteristics (e.g., age, sex, and ethnicity) and lifestyle (e.g., physical activity level and smoking status).

However, despite these problems, some findings emerge clearly from the studies conducted so far. Firstly, the results of the studies reported in Table 1, taken together, emphasized the fact that plasma PCO levels are increased in adult or elderly patients with CKD compared to healthy subjects.
Even in the early stages of CKD, plasma PCO levels are elevated, and they increase from one stage to the next one, as the kidney function declines over time. This supports the conclusion that systemic oxidative stress appears already at the initial stages of CKD and it gradually increases along with the severity of the disease. Few data are present in the literature about PCO levels in people younger than 18 years. The only study in this setting showed that, in children and young patients with CKD stages 1-5, the concentration of plasma PCO did not depend on the stage of disease [51]. In addition, plasma PCO levels from adult or elderly patients with CKD seem to be correlated negatively with GFR [47-49] and positively with BUN [48], even if caution is necessary to interpret these small studies.

Secondly, studies measuring plasma PCO levels in ESRD patients on PD vs. ESRD patients on HD have generated conflicting results [44, 50, 108-110] (Table 3). Maybe this could be due to interfering factors such as the different RRF between ESRD patients undergoing $\mathrm{HD}$ or PD. In fact, RRF decreases more slowly in people undergoing $\mathrm{PD}$ than in those undergoing HD $[117,118]$, probably because of sudden drops in blood pressure typical of HD, where fluid is removed much more quickly during the short and frequent HD sessions as compared to the longer PD cycles. In addition, other factors can influence RRF decline, such as gender (particularly female gender as being associated with a stronger decline), nonwhite race (associated with a stronger decline), and comorbidities [103, 119]. A further limitation of these studies was the relatively small number of patients.

Thirdly, after the restoration of kidney function by transplantation, plasma PCO content lowers to levels similar to those of healthy control subjects. Although the populations involved were limited in size, several studies support the conclusion that KT reduces oxidative stress [49, 115, 120, 121].

In conclusion, the studies presented in this review demonstrate that oxidative stress is higher in CKD. Western blot analysis with anti-DNP antibodies showed that not all proteins in the plasma of CKD patients are prone to carbonylation, supporting the view that protein carbonylation in $\mathrm{CKD}$ is a selective rather than a random process. In patients with various stages of CKD [44] and in ESRD patients on $\mathrm{HD}$, carbonylation affects albumin [41, 44, 89-91] and other proteins present in the plasma in lower amounts $[36,37]$. Direct, or primary, carbonylation is a protein irreversible damage, an oxidative modification that cannot be reversed by antioxidant defences $[22,25,122,123]$. The increased carbonylation of proteins directly leads to the central unsolved question: does the carbonylation of proteins have a direct pathological impact or is it a secondary phenomenon? Albumin, along with ascorbate and urate, represents the most important antioxidants in the plasma [124]. As albumin is carbonylated in CKD patients, including ESRD patients on $\mathrm{HD}$, it can be hypothesized that, in these subjects, the plasma antioxidant defences are lower and, consequently, the risk for oxidative tissue damage is higher [125]. Several studies conducted in ESRD patients on HD have indeed demonstrated that albumin carbonylation can adversely affect its vasculoprotective capabilities $[89,90]$, fibrinogen carbonylation can contribute to the impaired clotting activity [126], and 
carbonylation of haptoglobin and ceruloplasmin [36, 37] can impair the antioxidant protective properties of these proteins.

Overall, all these studies point out that plasma protein carbonylation in CKD, and especially in ESRD patients undergoing $\mathrm{HD}$, is not solely a secondary phenomenon. Despite the fact that the role of plasma PCO in CKD is often underestimated in clinical practice, emerging evidence continues to highlight that plasma PCO can serve as good biomarkers of oxidative stress in CKD and substitutive therapies, $\mathrm{HD}, \mathrm{PD}$, and $\mathrm{KT}$. Whether plasma PCO levels merely serve as biomarkers of CKD- and RRT-related oxidative stress or whether they are associated with the pathogenesis of CKD complications deserves further evaluation. In this regard, it is interesting to note that advanced glycation end products (AGEs), i.e., glycated amino acid residues of proteins, contribute to the development of CKD [127]. AGEs are stable posttranslational modified proteins derived by the nonenzymatic reaction of reducing sugars and related metabolites with Arg and Lys residues, giving rise to indirect, or secondary, protein carbonylation. Proteolysis of AGEs produces glycated amino acids, or AGE-free adducts, which are cleared by the kidneys under healthy conditions but accumulate in plasma with the decline in GFR during CKD [127, 128]. AGEs also result from dicarbonyls derived from glucose degradation and absorbed from thermally processed dialysis fluids in RRT and from the so-called dicarbonyl stress, i.e., the accumulation of various dicarbonyl compounds that causes increased AGE formation in people with CKD [127, 129]. In patients with ESRD, plasma AGE-free adducts increased up to 18-fold on PD and up to 40-fold on HD, whereas the increase in AGE residues of plasma proteins was 2- to 5-fold [128]. Protein dysfunction and inactivation caused by AGE formation contribute to CKD development [127]. Indeed, several studies that investigated dysfunction of proteins modified by dicarbonyl compounds-the socalled dicarbonyl proteome-suggest that dicarbonyl stress is a key factor for the development of vascular renal inflammation, kidney and muscle fibrosis, which are critical to CKD progression and comorbidities, CVD, and muscle wasting $[127,130]$.

\section{Abbreviations}

$\begin{array}{ll}\text { BUN: } & \text { Blood urea nitrogen } \\ \text { CKD: } & \text { Chronic kidney disease } \\ \text { CRP: } & \text { C-reactive protein } \\ \text { CT: } & \text { Conservative therapy } \\ \text { CVD: } & \text { Cardiovascular disease } \\ \text { DNP: } & \text { 2,4-Dinitrophenylhydrazone } \\ \text { DNPH: } & \text { 2,4-Dinitrophenylhydrazine } \\ \text { ELISA: } & \text { Enzyme-linked immunosorbent assay } \\ \text { ESRD: } & \text { End-stage renal disease } \\ \text { GFR: } & \text { Glomerular filtration rate } \\ \text { HD: } & \text { Haemodialysis } \\ \text { HRP: } & \text { Horseradish peroxidase } \\ \text { KDIGO: } & \text { Kidney Disease Improving Global Outcomes } \\ \text { KT: } & \text { Kidney transplantation } \\ \text { MALDI-TOF: } & \end{array}$

Matrix-assisted laser desorption/ionization time-of-flight

MS: $\quad$ Mass spectrometry

PCO: $\quad$ Protein carbonyls (carbonylated proteins)

PD: $\quad$ Peritoneal dialysis

PVDF: $\quad$ Polyvinylidene fluoride membrane

ROS: $\quad$ Reactive oxygen species

RRF: Residual renal function

RRT: Renal replacement therapy.

\section{Conflicts of Interest}

We wish to confirm that there are no known conflicts of interest associated with this publication.

\section{Authors' Contributions}

We further confirm that the manuscript has been read and approved by all named authors and that the order of authors listed in the manuscript has been approved by all of us.

\section{Acknowledgments}

This work was supported by the "Fondazione Humanitas."

\section{Supplementary Materials}

Table 4: patient selection. CKD or RRT inclusion and/or exclusion criteria in various studies $[37,41,45-52,66,76$, 78, 79, 81-84, 86, 87, 90-92, 98, 109-112, 116, 132-139]. (Supplementary Materials)

\section{References}

[1] V. Jha, G. Garcia-Garcia, K. Iseki et al., "Chronic kidney disease: global dimension and perspectives," Lancet, vol. 382, no. 9888, pp. 260-272, 2013.

[2] KDIGO Kidney Disease, "Improving global outcomes CKD work group. KDIGO 2012 clinical practice guideline for the evaluation and management of chronic kidney disease," Kidney International Supplements, vol. 3, pp. 1-150, 2013.

[3] M. J. Sarnak, A. S. Levey, A. C. Schoolwerth et al., "Kidney disease as a risk factor for development of cardiovascular disease: a statement from the American Heart Association councils on kidney in cardiovascular disease, high blood pressure research, clinical cardiology, and epidemiology and prevention," Circulation, vol. 108, no. 17, pp. 2154-2169, 2003.

[4] P. Stenvinkel, J. J. Carrero, J. Axelsson, B. Lindholm, O. Heimbürger, and Z. Massy, "Emerging biomarkers for evaluating cardiovascular risk in the chronic kidney disease patient: how do new pieces fit into the uremic puzzle?," Clinical Journal of the American Society of Nephrology, vol. 3, no. 2, pp. 505-521, 2008.

[5] P. Muntner, J. He, B. C. Astor, A. R. Folsom, and J. Coresh, "Traditional and nontraditional risk factors predict coronary heart disease in chronic kidney disease: results from the Atherosclerosis Risk in Communities study," Journal of the American Society of Nephrology, vol. 16, no. 2, pp. 529-538, 2005.

[6] V. Cachofeiro, M. Goicochea, S. G. de Vinuesa, P. Oubiña, V. Lahera, and J. Luño, "Oxidative stress and inflammation, 
a link between chronic kidney disease and cardiovascular disease," Kidney International. Supplement, vol. 74, pp. S4-S9, 2008.

[7] J. J. Carrero and P. Stenvinkel, "Persistent inflammation as a catalyst for other risk factors in chronic kidney disease: a hypothesis proposal," Clinical Journal of the American Society of Nephrology, vol. 4, Supplement 1, pp. S49-S55, 2009.

[8] T. Miyamoto, J. J. Carrero, and P. Stenvinkel, "Inflammation as a risk factor and target for therapy in chronic kidney disease," Current Opinion in Nephrology and Hypertension, vol. 20, no. 6, pp. 662-668, 2011.

[9] P. S. Tucker, A. T. Scanlan, and V. J. Dalbo, "Chronic kidney disease influences multiple systems: describing the relationship between oxidative stress, inflammation, kidney damage, and concomitant disease," Oxidative Medicine and Cellular Longevity, vol. 2015, Article ID 806358, 8 pages, 2015.

[10] J. Himmelfarb, P. Stenvinkel, T. A. Ikizler, and R. M. Hakim, "The elephant in uremia: oxidant stress as a unifying concept of cardiovascular disease in uremia," Kidney International, vol. 62 , no. 5, pp. 1524-1538, 2002.

[11] S. Ruiz, P. E. Pergola, R. A. Zager, and N. D. Vaziri, “Targeting the transcription factor Nrf 2 to ameliorate oxidative stress and inflammation in chronic kidney disease," Kidney International, vol. 83, no. 6, pp. 1029-1041, 2013.

[12] S. F. Rapa, B. R. di Iorio, P. Campiglia, A. Heidland, and S. Marzocco, "Inflammation and oxidative stress in chronic kidney disease-potential therapeutic role of minerals, vitamins and plant-derived metabolites," International Journal of Molecular Sciences, vol. 21, no. 1, p. 263, 2020.

[13] A. Popolo, G. Autore, A. Pinto, and S. Marzocco, "Oxidative stress in patients with cardiovascular disease and chronic renal failure," Free Radical Research, vol. 47, no. 5, pp. 346356, 2013.

[14] M. Morena, S. Delbosc, A.-M. Dupuy, B. Canaud, and J.P. Cristol, "Overproduction of reactive oxygen species in end-stage renal disease patients: a potential component of hemodialysis-associated inflammation," Hemodialysis International, vol. 9, no. 1, pp. 37-46, 2005.

[15] S. Mihai, E. Codrici, I. D. Popescu et al., "Inflammationrelated mechanisms in chronic kidney disease prediction, progression and outcome," Journal of Immunology Research, vol. 2018, Article ID 2180373, 16 pages, 2018.

[16] E. Dounousi, E. Papavasiliou, A. Makedou et al., "Oxidative stress is progressively enhanced with advancing stages of CKD," American Journal of Kidney Diseases, vol. 48, no. 5, pp. 752-760, 2006.

[17] V. Liakopoulos, S. Roumeliotis, X. Gorny, E. Dounousi, and P. R. Mertens, "Oxidative stress in hemodialysis patients: a review of the literature," Oxidative Medicine and Cellular Longevity, vol. 2017, Article ID 3081856, 22 pages, 2017.

[18] B. Ferraro, F. Galli, B. Frei et al., "Peroxynitrite-induced oxidation of plasma lipids is enhanced in stable hemodialysis patients," Kidney International, vol. 63, no. 6, pp. 22072213, 2003.

[19] V. Liakopoulos, S. Roumeliotis, S. Zarogiannis, T. Eleftheriadis, and P. R. Mertens, "Oxidative stress in hemodialysis: causative mechanisms, clinical implications, and possible therapeutic interventions," Seminars in Dialysis, vol. 32, no. 1, pp. 58-71, 2019.

[20] V. Liakopoulos, S. Roumeliotis, X. Gorny, T. Eleftheriadis, and P. R. Mertens, "Oxidative stress in patients undergoing peritoneal dialysis: a current review of the literature," Oxidative Medicine and Cellular Longevity, vol. 2017, Article ID 3494867, 14 pages, 2017.

[21] S. Roumeliotis, T. Eleftheriadis, and V. Liakopoulos, "Is oxidative stress an issue in peritoneal dialysis?" Seminars in Dialysis, vol. 32, no. 5, pp. 463-466, 2019.

[22] J. Frijhoff, P. G. Winyard, N. Zarkovic et al., "Clinical relevance of biomarkers of oxidative stress," Antioxidants \& Redox Signaling, vol. 23, no. 14, pp. 1144-1170, 2015.

[23] I. Six, N. Flissi, G. Lenglet et al., "Uremic toxins and vascular dysfunction," Toxins, vol. 12, no. 6, p. 404, 2020.

[24] M. Diaz-Ricart, S. Torramade-Moix, G. Pascual et al., "Endothelial damage, inflammation and immunity in chronic kidney disease," Toxins, vol. 12, no. 6, p. 361, 2020.

[25] I. Dalle-Donne, G. Aldini, M. Carini, R. Colombo, R. Rossi, and A. Milzani, "Protein carbonylation, cellular dysfunction, and disease progression," Journal of Cellular and Molecular Medicine, vol. 10, no. 2, pp. 389-406, 2006.

[26] A. Bachi, I. Dalle-Donne, and A. Scaloni, "Redox proteomics: chemical principles, methodological approaches and biological/biomedical promises," Chemical Reviews, vol. 113, no. 1, pp. 596-698, 2013.

[27] I. Dalle-Donne, R. Rossi, D. Giustarini, A. Milzani, and R. Colombo, "Protein carbonyl groups as biomarkers of oxidative stress," Clinica Chimica Acta, vol. 329, no. 1-2, pp. 23-38, 2003.

[28] I. Dalle-Donne, R. Rossi, R. Colombo, D. Giustarini, and A. Milzani, "Biomarkers of oxidative damage in human disease," Clinical Chemistry, vol. 52, no. 4, pp. 601-623, 2006.

[29] P. S. Tucker, V. J. Dalbo, T. Han, and M. I. Kingsley, "Clinical and research markers of oxidative stress in chronic kidney disease," Biomarkers, vol. 18, no. 2, pp. 103-115, 2013.

[30] K. P. Poulianiti, A. Kaltsatou, G. I. Mitrou et al., "Systemic redox imbalance in chronic kidney disease: a systematic review," Oxidative Medicine and Cellular Longevity, vol. 2016, Article ID 8598253, 19 pages, 2016.

[31] R. L. Levine, N. Wehr, J. A. Williams, E. R. Stadtman, and E. Shacter, "Determination of carbonyl groups in oxidized proteins," Methods in Molecular Biology, vol. 99, pp. 15-24, 2000.

[32] I. H. Buss and C. C. Winterbourn, "Protein carbonyl measurement by ELISA," Methods in Molecular Biology, vol. 186, pp. 123-128, 2002.

[33] D. Alamdari, E. Kostidou, K. Paletas et al., "High sensitivity enzyme-linked immunosorbent assay (ELISA) method for measuring protein carbonyl in samples with low amounts of protein," Free Radical Biology \& Medicine, vol. 39, no. 10, pp. 1362-1367, 2005.

[34] G. Colombo, M. Clerici, M. E. Garavaglia et al., "A step-bystep protocol for assaying protein carbonylation in biological samples," Journal of Chromatography. B, Analytical Technologies in the Biomedical and Life Sciences, vol. 1019, pp. 178190, 2016.

[35] G. Colombo, M. Clerici, A. Altomare et al., "Thiol oxidation and di-tyrosine formation in human plasma proteins induced by inflammatory concentrations of hypochlorous acid," Journal of Proteomics, vol. 152, pp. 22-32, 2017.

[36] B. Pavone, V. Sirolli, S. Bucci et al., "Adsorption and carbonylation of plasma proteins by dialyser membrane material: in vitro and in vivo proteomics investigations," Blood Transfusion, vol. 8 Suppl 3, 8 Supplement 3, pp. s113-s119, 2010. 
[37] B. Pavone, V. Sirolli, A. Giardinelli et al., "Plasma protein carbonylation in chronic uremia," Journal of Nephrology, vol. 24, no. 4, pp. 453-464, 2011.

[38] G. Colombo, I. Dalle-Donne, M. Orioli et al., "Oxidative damage in human gingival fibroblasts exposed to cigarette smoke," Free Radical Biology \& Medicine, vol. 52, no. 9, pp. 1584-1596, 2012.

[39] I. Climent, L. Tsai, and R. L. Levine, "Derivatization of gamma-glutamyl semialdehyde residues in oxidized proteins by fluoresceinamine," Analytical Biochemistry, vol. 182, no. 2, pp. 226-232, 1989.

[40] G. Colombo, F. Reggiani, D. Cucchiari et al., "Plasma proteinbound di-tyrosines as biomarkers of oxidative stress in end stage renal disease patients on maintenance haemodialysis," BBA Clinical, vol. 7, pp. 55-63, 2017.

[41] G. Colombo, F. Reggiani, D. Cucchiari et al., "Plasma protein carbonylation in haemodialysed patients: focus on diabetes and gender," Oxidative Medicine and Cellular Longevity, vol. 2018, Article ID 4149681, 12 pages, 2018.

[42] G. Colombo, F. Reggiani, E. Astori et al., "Advanced oxidation protein products in nondiabetic end stage renal disease patients on maintenance haemodialysis," Free Radical Research, vol. 53, no. 11-12, pp. 1114-1124, 2019.

[43] D. Weber, M. J. Davies, and T. Grune, "Determination of protein carbonyls in plasma, cell extracts, tissue homogenates, isolated proteins: focus on sample preparation and derivatization conditions," Redox Biology, vol. 5, pp. 367380, 2015.

[44] Z. Mitrogianni, A. Barbouti, D. Galaris, and K. C. Siamopoulos, "Oxidative modification of albumin in predialysis, hemodialysis, and peritoneal dialysis patients," Nephron. Clinical Practice, vol. 113, no. 3, pp. c234-c240, 2009.

[45] B. P. Oberg, E. McMenamin, F. L. E. E. Lucas et al., "Increased prevalence of oxidant stress and inflammation in patients with moderate to severe chronic kidney disease," Kidney International, vol. 65, no. 3, pp. 1009-1016, 2004.

[46] M. J. Puchades Montesa, M. A. González Rico, M. A. Solís Salguero et al., "Study of oxidative stress in advanced kidney disease," Nefrología, vol. 29, no. 5, pp. 464-473, 2009.

[47] G. Caimi, C. Carollo, E. Hopps, M. Montana, and R. Lo Presti, "Protein oxidation in chronic kidney disease," Clinical Hemorheology and Microcirculation, vol. 54, no. 4, pp. 409-413, 2013.

[48] Y. Matsuyama, H. Terawaki, T. Terada, and S. Era, “Albumin thiol oxidation and serum protein carbonyl formation are progressively enhanced with advancing stages of chronic kidney disease," Clinical and Experimental Nephrology, vol. 13, no. 4, pp. 308-315, 2009.

[49] P. R. Aveles, C. R. Criminácio, S. Gonçalves et al., “Association between biomarkers of carbonyl stress with increased systemic inflammatory response in different stages of chronic kidney disease and after renal transplantation," Nephron. Clinical Practice, vol. 116, no. 4, pp. c294-c299, 2010.

[50] H. F. Tbahriti, A. Kaddous, M. Bouchenak, and K. Mekki, "Effect of different stages of chronic kidney disease and renal replacement therapies on oxidant-antioxidant balance in uremic patients," Biochemistry Research International, vol. 2013, Article ID 358985, 6 pages, 2013.

[51] D. Drożdż, P. Kwinta, K. Sztefko et al., "Oxidative stress biomarkers and left ventricular hypertrophy in children with chronic kidney disease," Oxidative Medicine and Cellular Longevity, vol. 2016, Article ID 7520231, 8 pages, 2016.
[52] F. Locatelli, B. Canaud, K. U. Eckardt, P. Stenvinkel, C. Wanner, and C. Zoccali, "Oxidative stress in end-stage renal disease: an emerging threat to patient outcome," Nephrology, Dialysis, Transplantation, vol. 18, no. 7, pp. 1272-1280, 2003.

[53] K. Caglar, Y. Peng, L. B. Pupim et al., "Inflammatory signals associated with hemodialysis," Kidney International, vol. 62, no. 4, pp. 1408-1416, 2002.

[54] P. Susantitaphong, C. Riella, and B. L. Jaber, "Effect of ultrapure dialysate on markers of inflammation, oxidative stress, nutrition and anemia parameters: a meta-analysis," Nephrology, Dialysis, Transplantation, vol. 28, no. 2, pp. 438-446, 2013.

[55] G. Glorieux, N. Neirynck, N. Veys, and R. Vanholder, "Dialysis water and fluid purity: more than endotoxin," Nephrology, Dialysis, Transplantation, vol. 27, no. 11, pp. 40104021, 2012.

[56] R. Jofré, P. Rodriguez-Benitez, J. M. López-Gómez, and R. Pérez-Garcia, "Inflammatory syndrome in patients on hemodialysis," Journal of the American Society of Nephrology, vol. 17, 12 supplement 3, pp. S274-S280, 2006.

[57] T. B. Drüeke and P. S. Parfrey, "Summary of the KDIGO guideline on anemia and comment: reading between the (guide)line(s)," Kidney International, vol. 82, no. 9, pp. 952-960, 2012.

[58] J. L. Babitt and H. Y. Lin, "Molecular mechanisms of hepcidin regulation: implications for the anemia of CKD," American Journal of Kidney Diseases, vol. 55, no. 4, pp. 726-741, 2010.

[59] G. Tsagalis, "Renal anemia: a nephrologist's view," Hyppokratia, vol. 15, Suppl 1, pp. 39-43, 2011.

[60] K. Zumbrennen-Bullough and J. L. Babitt, "The iron cycle in chronic kidney disease (CKD): from genetics and experimental models to CKD patients," Nephrology, Dialysis, Transplantation, vol. 29, no. 2, pp. 263-273, 2014.

[61] I. C. Macdougall, A. J. Bircher, K.-U. Eckardt et al., "Iron management in chronic kidney disease: conclusions from a "Kidney Disease: Improving Global Outcomes" (KDIGO) controversies conference," Kidney International, vol. 89, no. 1, pp. 28-39, 2016.

[62] K. Pawlak, D. Pawlak, and M. Mysliwiec, "Long-term erythropoietin therapy does not affect endothelial markers, coagulation activation and oxidative stress in haemodialyzed patients," Thrombosis Research, vol. 120, no. 6, pp. 797803, 2007.

[63] X. Li, A. V. Kshirsagar, and M. A. Brookhart, "Safety of intravenous iron in hemodialysis patients," Hemodialysis International, vol. 21, pp. S93-S103, 2017.

[64] L. Del Vecchio, S. Longhi, and F. Locatelli, "Safety concerns about intravenous iron therapy in patients with chronic kidney disease," Clinical Kidney Journal, vol. 9, no. 2, pp. 260267, 2016.

[65] B. Murillo-Ortiz, J. Ramírez Emiliano, W. I. Hernández Vázquez et al., "Impact of oxidative stress in premature aging and iron overload in hemodialysis patients," Oxidative Medicine and Cellular Longevity, vol. 2016, Article ID 1578235, 8 pages, 2016.

[66] P. Stenvinkel, "Inflammation in end-stage renal disease: the hidden enemy," Nephrology (Carlton), vol. 11, no. 1, pp. 3641, 2006.

[67] J. J. Carrero and P. Stenvinkel, "Inflammation in end-stage renal disease: what have we learned in 10 years?" Seminars in Dialysis, vol. 23, no. 5, pp. 498-509, 2010. 
[68] C. L. Meuwese, P. Stenvinkel, F. W. Dekker, and J. J. Carrero, "Monitoring of inflammation in patients on dialysis: forewarned is forearmed," Nature Reviews. Nephrology, vol. 7, no. 3, pp. 166-176, 2011.

[69] S. Oldani, S. Finazzi, B. Bottazzi et al., "Plasma pentraxin-3 as a marker of bioincompatibility in hemodialysis patients," Journal of Nephrology, vol. 25, no. 1, pp. 120-126, 2012.

[70] W. Zhang, J. He, F. Zhang et al., "Prognostic role of Creactive protein and interleukin-6 in dialysis patients: a systematic review and meta-analysis," Journal of Nephrology, vol. 26, no. 2, pp. 243-253, 2013.

[71] K. Khazim, D. Giustarini, R. Rossi et al., "Glutathione redox potential is low and glutathionylated and cysteinylated hemoglobin levels are elevated in maintenance hemodialysis patients," Translational Research, vol. 162, no. 1, pp. 16-25, 2013.

[72] G. Colombo, F. Reggiani, M. A. Podestà et al., "Plasma protein thiolation index (PTI) as a biomarker of thiol-specific oxidative stress in haemodialyzed patients," Free Radical Biology \& Medicine, vol. 89, pp. 443-451, 2015.

[73] P. Fanti, D. Giustarini, R. Rossi et al., "Dietary intake of proteins and calories is inversely associated with the oxidation state of plasma thiols in end-stage renal disease patients," Journal of Renal Nutrition, vol. 25, no. 6, pp. 494-503, 2015.

[74] G. Colombo, M. Clerici, D. Giustarini et al., "A central role for intermolecular dityrosine cross-linking of fibrinogen in high molecular weight advanced oxidation protein product (AOPP) formation," Biochimica et Biophysica Acta, vol. 1850, no. 1, pp. 1-12, 2015.

[75] L. B. Pupim, J. Himmelfarb, E. McMonagle, Y. Shyr, and T. A. Ikizler, "Influence of initiation of maintenance hemodialysis on biomarkers of inflammation and oxidative stress," Kidney International, vol. 65, no. 6, pp. 2371-2379, 2004.

[76] C. H. den Hoedt, M. L. Bots, M. P. C. Grooteman et al., "Clinical predictors of decline in nutritional parameters over time in ESRD," Clinical Journal of the American Society of Nephrology, vol. 9, no. 2, pp. 318-325, 2014.

[77] T. Köken, M. Serteser, A. Kahraman, C. Gökçe, and S. Demir, "Changes in serum markers of oxidative stress with varying periods of haemodialysis," Nephrology (Carlton), vol. 9, no. 2, pp. 77-82, 2004.

[78] T. Koca, A. Berber, H. B. Koca, T. A. Demir, and T. Koken, "Effects of hemodialysis period on levels of blood trace elements and oxidative stress," Clinical and Experimental Nephrology, vol. 14, no. 5, pp. 463-468, 2010.

[79] R. Dahwa, R. G. Fassett, Z. Wang, D. Briskey, A. R. Mallard, and J. S. Coombes, "Variability of oxidative stress biomarkers in hemodialysis patients," Biomarkers, vol. 19, no. 2, pp. 154158, 2014.

[80] R. A. Ward, R. Ouseph, and K. R. McLeish, "Effects of highflux hemodialysis on oxidant stress," Kidney International, vol. 63, no. 1, pp. 353-359, 2003.

[81] E. Dursun, B. Dursun, G. Süleymanlar, and T. Ozben, "Carbonyl stress in chronic renal failure: the effect of haemodialysis," Annals of Clinical Biochemistry, vol. 42, no. 1, pp. 64-66, 2005.

[82] A. Pieniazek, J. Brzeszczynska, I. Kruszynska, and K. Gwozdzinski, "Investigation of albumin properties in patients with chronic renal failure," Free Radical Research, vol. 43, no. 10, pp. 1008-1018, 2009.

[83] K. Albarello, G. A. dos Santos, G. V. Bochi et al., "Ischemia modified albumin and carbonyl protein as potential bio- markers of protein oxidation in hemodialysis," Clinical Biochemistry, vol. 45, no. 6, pp. 450-454, 2012.

[84] G. Caimi, E. Hopps, M. Montana et al., "Behaviour of carbonyl groups in several clinical conditions: analysis of our survey," Clinical Hemorheology and Microcirculation, vol. 74, no. 3, pp. 299-313, 2020.

[85] W. Siems, F. Carluccio, S. Radenkovic, T. Grune, and H. Hampl, "Oxidative stress in renal anemia of hemodialysis patients is mitigated by epoetin treatment," Kidney \& Blood Pressure Research, vol. 28, no. 5-6, pp. 295-301, 2006.

[86] H. Terawaki, Y. Takada, S. Era et al., "The redox state of albumin and serious cardiovascular incidence in hemodialysis patients," Therapeutic Apheresis and Dialysis, vol. 14, no. 5, pp. $465-471,2010$.

[87] M. Herselman, N. Esau, J. M. Kruger, D. Labadarios, and M. R. Moosa, "Relationship between serum protein and mortality in adults on long-term hemodialysis: exhaustive review and meta-analysis," Nutrition, vol. 26, no. 1, pp. 10-32, 2010.

[88] R. Mehrotra, U. Duong, S. Jiwakanon et al., "Serum albumin as a predictor of mortality in peritoneal dialysis: comparisons with hemodialysis," American Journal of Kidney Diseases, vol. 58, no. 3, pp. 418-428, 2011.

[89] J. Himmelfarb and E. McMonagle, "Albumin is the major plasma protein target of oxidant stress in uremia," Kidney International, vol. 60, no. 1, pp. 358-363, 2001.

[90] P. S. Lim, Y. M. Cheng, and S. M. Yang, "Impairments of the biological properties of serum albumin in patients on haemodialysis," Nephrology (Carlton), vol. 12, no. 1, pp. 18-24, 2007.

[91] M. Anraku, K. Kitamura, A. Shinohara et al., "Intravenous iron administration induces oxidation of serum albumin in hemodialysis patients," Kidney International, vol. 66, no. 2, pp. 841-848, 2004.

[92] S. F. Leavey, R. L. Strawderman, E. W. Young et al., "Crosssectional and longitudinal predictors of serum albumin in hemodialysis patients," Kidney International, vol. 58, no. 5, pp. 2119-2128, 2000.

[93] J. D. Burrowes, D. B. Cockram, J. T. Dwyer et al., "Cross-sectional relationship between dietary protein and energy intake, nutritional status, functional status, and comorbidity in older versus younger hemodialysis patients," Journal of Renal Nutrition, vol. 12, no. 2, pp. 87-95, 2002.

[94] G. A. Kaysen, J. A. Dubin, H.-G. Müller et al., "Inflammation and reduced albumin synthesis associated with stable decline in serum albumin in hemodialysis patients," Kidney International, vol. 65, no. 4, pp. 1408-1415, 2004.

[95] K. Kalantar-Zadeh, R. D. Kilpatrick, N. Kuwae et al., "Revisiting mortality predictability of serum albumin in the dialysis population: time dependency, longitudinal changes and population-attributable fraction," Nephrology, Dialysis, Transplantation, vol. 20, no. 9, pp. 1880-1888, 2005.

[96] H. Honda, A. R. Qureshi, O. Heimbürger et al., "Serum albumin, C-reactive protein, interleukin 6 , and fetuin a as predictors of malnutrition, cardiovascular disease, and mortality in patients with ESRD," American Journal of Kidney Diseases, vol. 47, no. 1, pp. 139-148, 2006.

[97] M. Danielski, T. A. Ikizler, E. McMonagle et al., "Linkage of hypoalbuminemia, inflammation, and oxidative stress in patients receiving maintenance hemodialysis therapy," American Journal of Kidney Diseases, vol. 42, no. 2, pp. 286-294, 2003.

[98] P. K.-T. Li, K. M. Chow, M. W. M. van de Luijtgaarden et al., "Changes in the worldwide epidemiology of peritoneal 
dialysis," Nature Reviews. Nephrology, vol. 13, no. 2, pp. 90103, 2017.

[99] J. T. Daugirdas, P. G. Blake, and T. S. Ing, Handbook of Dial$y$ sis, 5th edition5th edition, , 2015.

[100] R. Gokal, "Peritoneal dialysis in the 21st century: an analysis of current problems and further developments," Journal of the American Society of Nephrology, vol. 13, supplement 1, pp. S104-S115, 2002.

[101] D. W. Johnson, K. Armstrong, S. B. Campbell et al., "Metabolic syndrome in severe chronic kidney disease: prevalence, predictors, prognostic significance and effects of risk factor modification," Nephrology, vol. 12, no. 4, pp. 391-398, 2007.

[102] E. Kimak, J. Solski, L. Janicka, A. Ksaziek, and K. Janicki, "Concentration of $\mathrm{Lp}(\mathrm{a})$ and other apolipoproteins in predialysis, hemodialysis, chronic ambulatory peritoneal dialysis and post-transplant patients," Clinical Chemistry and Laboratory Medicine, vol. 38, no. 5, pp. 421-425, 2000.

[103] L. M. Moist, F. K. Port, S. M. Orzol et al., "Predictors of loss of residual renal function among new dialysis patients," Journal of the American Society of Nephrology, vol. 11, no. 3, pp. 556564, 2000.

[104] R. Dikow, V. Schwenger, M. Zeier, and E. Ritz, "Do AV fistulas contribute to cardiac mortality in hemodialysis patients?," Seminars in Dialysis, vol. 15, no. 1, pp. 14-17, 2002.

[105] F. Galli, "Protein damage and inflammation in uraemia and dialysis patients," Nephrology Dialysis Transplantation, vol. 22, Supplement 5, pp. v20-v36, 2007.

[106] S. Müller-Krebs, L. P. Kihm, B. Zeier et al., "Glucose degradation products result in cardiovascular toxicity in a rat model of renal failure," Peritoneal Dialysis International: Journal of the International Society for Peritoneal Dialysis, vol. 30, no. 1, pp. 35-40, 2010.

[107] D. C. Tarng, T. Wen Chen, T. P. Huang, C. L. Chen, T. Y. Liu, and Y. H. Wei, "Increased oxidative damage to peripheral blood leukocyte dna in chronic peritoneal dialysis patients," Journal of the American Society of Nephrology, vol. 13, no. 5, pp. 1321-1330, 2002.

[108] C. Erdoğan, Y. Unlüçerçi, A. Türkmen, A. Kuru, O. Cetin, and S. Bekpinar, "The evaluation of oxidative stress in patients with chronic renal failure," Clinica Chimica Acta, vol. 322, no. 1-2, pp. 157-161, 2002.

[109] T. Doñate, A. Herreros, E. Martinez et al., "Protein oxidative stress in dialysis patients," Advances in peritoneal dialysis. Conference on Peritoneal Dialysis, vol. 18, pp. 15-17, 2002.

[110] K. Mekki, W. Taleb, N. Bouzidi, A. Kaddous, and M. Bouchenak, "Effect of hemodialysis and peritoneal dialysis on redox status in chronic renal failure patients: a comparative study," Lipids in Health and Disease, vol. 9, no. 1, p. 93, 2010.

[111] C. H. Guo, P. C. Chen, M. S. Yeh, D. Y. Hsiung, and C. L. Wang, " $\mathrm{Cu} / \mathrm{Zn}$ ratios are associated with nutritional status, oxidative stress, inflammation, and immune abnormalities in patients on peritoneal dialysis," Clinical Biochemistry, vol. 44, no. 4, pp. 275-280, 2011.

[112] A. Ortiz, A. Covic, D. Fliser et al., "Epidemiology, contributors to, and clinical trials of mortality risk in chronic kidney failure," Lancet, vol. 383, no. 9931, pp. 1831-1843, 2014.

[113] M. Campise, F. Bamonti, C. Novembrino et al., "Oxidative stress in kidney transplant patients1," Transplantation, vol. 76, no. 10, pp. 1474-1478, 2003.
[114] E. Malle, T. Buch, and H.-J. Grone, "Myeloperoxidase in kidney disease," Kidney International, vol. 64, no. 6, pp. 19561967, 2003.

[115] E. M. Simmons, A. Langone, M. T. Sezer et al., "Effect of renal transplantation on biomarkers of inflammation and oxidative stress in end-stage renal disease patients," Transplantation, vol. 79, no. 8, pp. 914-919, 2005.

[116] L. J. Yan and M. J. Forster, "Chemical probes for analysis of carbonylated proteins: a review," Journal of Chromatography. B, Analytical Technologies in the Biomedical and Life Sciences, vol. 879, no. 17-18, pp. 1308-1315, 2011.

[117] M. Misra, E. Vonesh, J. C. Van Stone, H. L. Moore, B. Prowant, and K. D. Nolph, "Effect of cause and time of dropout on the residual GFR: a comparative analysis of the decline of GFR on dialysis," Kidney International, vol. 59, no. 2, pp. 754-763, 2001.

[118] B. Marrón, C. Remón, M. Pérez-Fontán, P. Quirós, and A. Ortíz, "Benefits of preserving residual renal function in peritoneal dialysis," Kidney International. Supplement, vol. 73, Supplement 108, pp. S42-S51, 2008.

[119] M. A. M. Jansen, A. A. M. Hart, J. C. Korevaar, F. W. Dekker, E. W. Boeschoten, and R. T. Krediet, "Predictors of the rate of decline of residual renal function in incident dialysis patients," Kidney International, vol. 62, no. 3, pp. 10461053, 2002.

[120] J. Vostálová, A. Galandáková, A. R. Svobodová et al., "Timecourse evaluation of oxidative stress-related biomarkers after renal transplantation," Renal Failure, vol. 34, no. 4, pp. 413419, 2012.

[121] J. I. Cerrillos-Gutiérrez, A. G. Miranda-Díaz, P. PreciadoRojas et al., "The beneficial effects of renal transplantation on altered oxidative status of ESRD patients," Oxidative Medicine and Cellular Longevity, vol. 2016, Article ID 5757645, 6 pages, 2016.

[122] E. R. Stadtman and R. L. Levine, "Free radical-mediated oxidation of free amino acids and amino acid residues in proteins," Amino Acids, vol. 25, no. 3-4, pp. 207-218, 2003.

[123] C.-M. Wong, G. Bansal, L. Marcocci, and Y. J. Suzuki, "Proposed role of primary protein carbonylation in cell signaling," Redox Report, vol. 17, no. 2, pp. 90-94, 2013.

[124] G. Colombo, M. Clerici, D. Giustarini, R. Rossi, A. Milzani, and I. Dalle-Donne, "Redox albuminomics: oxidized albumin in human diseases," Antioxidants and Redox Signaling, vol. 17, no. 11, pp. 1515-1527, 2012.

[125] M. Anraku, K. Takeuchi, H. Watanabe et al., "Quantitative analysis of cysteine-34 on the anitioxidative properties of human serum albumin in hemodialysis patients," Journal of Pharmaceutical Sciences, vol. 100, no. 9, pp. 39683976, 2011.

[126] R. Michelis, R. Gery, S. Sela et al., "Carbonyl stress induced by intravenous iron during haemodialysis," Nephrology, Dialysis, Transplantation, vol. 18, no. 5, pp. 924-930, 2003.

[127] N. Rabbani and P. J. Thornalley, "Advanced glycation end products in the pathogenesis of chronic kidney disease," Kidney International, vol. 93, no. 4, pp. 803-813, 2018.

[128] S. Agalou, N. Ahmed, R. Babaei-Jadidi, A. Dawnay, and P. J. Thornalley, "Profound mishandling of protein glycation degradation products in uremia and dialysis," Journal of the American Society of Nephrology, vol. 16, no. 5, pp. 14711485, 2005. 
[129] N. Rabbani and P. J. Thornalley, "Dicarbonyls (glyoxal, methylglyoxal, and 3-deoxyglucosone)," in Uremic Toxins: Niwa/Uremic Toxins, T. Niwa, Ed., pp. 177-192, John Wiley \& Sons, Inc., Hoboken, NJ, 2012.

[130] P. Stenvinkel, J. J. Carrero, F. von Walden, T. A. Ikizler, and G. A. Nader, "Muscle wasting in end-stage renal disease promulgates premature death: established, emerging and potential novel treatment strategies," Nephrology, Dialysis, Transplantation, vol. 31, no. 7, pp. 1070-1077, 2016.

[131] J. Himmelfarb, E. McMonagle, and E. McMenamin, "Plasma protein thiol oxidation and carbonyl formation in chronic renal failure," Kidney International, vol. 58, no. 6, pp. 25712578, 2000.

[132] T. Nguyen-Khoa, Z. A. Massy, J. P. De Bandt et al., "Oxidative stress and haemodialysis: role of inflammation and duration of dialysis treatment," Nephrology, Dialysis, Transplantation, vol. 16, no. 2, pp. 335-340, 2001.

[133] Z. A. Massy, D. Borderie, T. Nguyen-Khoa, T. B. Drüeke, O. G. Ekindjian, and B. Lacour, "Increased plasma Snitrosothiol levels in chronic haemodialysis patients," Nephrology, Dialysis, Transplantation, vol. 18, no. 1, pp. 153-157, 2003.

[134] G. Kalogerakis, A. M. Baker, S. Christov et al., "Oxidative stress and high-density lipoprotein function in type I diabetes and end-stage renal disease," Clinical Science, vol. 108, no. 6, pp. 497-506, 2005.

[135] K. Mera, M. Anraku, K. Kitamura, K. Nakajou, T. Maruyama, and M. Otagiri, "The structure and function of oxidized albumin in hemodialysis patients: its role in elevated oxidative stress via neutrophil burst," Biochemical and Biophysical Research Communications, vol. 334, no. 4, pp. 1322-1328, 2005.

[136] H. Moradi, M. V. Pahl, R. Elahimehr, and N. D. Vaziri, "Impaired antioxidant activity of high-density lipoprotein in chronic kidney disease," Translational Research, vol. 153, no. 2, pp. 77-85, 2009.

[137] S. G. de Almeida, J. P. R. Veiga, S. F. Arruda, C. F. Neves, and E. M. de Almeida Siqueira, "The association of markers of oxidative-inflammatory status with malnutrition in hemodialysis patients with serum ferritin lower than $500 \mathrm{ng} / \mathrm{mL}$," Jornal Brasileiro de Nefrologia, vol. 35, no. 1, pp. 6-12, 2013.

[138] G. Boudouris, I. I. Verginadis, Y. V. Simos et al., "Oxidative stress in patients treated with continuous ambulatory peritoneal dialysis (CAPD) and the significant role of vitamin C and E supplementation," International Urology and Nephrology, vol. 45, no. 4, pp. 1137-1144, 2013.

[139] C. C. Winterbourn and I. H. Buss, "Protein carbonyl measurement by enzyme-linked immunosorbent assay," Methods in Enzymology, vol. 300, pp. 106-111, 1999.

[140] E. Shacter, J. A. Williams, M. Lim, and R. L. Levine, "Differential susceptibility of plasma proteins to oxidative modification: examination by western blot immunoassay," Free Radical Biology \& Medicine, vol. 17, no. 5, pp. 429-437, 1994.

[141] R. L. Levine, D. Garland, C. N. Oliver et al., "[49] Determination of carbonyl content in oxidatively modified proteins," Methods in enzymology, vol. 186, pp. 464-478, 1990.
[142] A. Z. Reznick and L. Packer, "[38] Oxidative damage to proteins: spectrophotometric method for carbonyl assay," Methods in enzymology, vol. 233, pp. 357-363, 1994.

[143] H. Buss, T. P. Chan, K. B. Sluis, N. M. Domigan, and C. C. Winterbourn, "Protein carbonyl measurement by a sensitive ELISA method," Free Radical Biology \& Medicine, vol. 23, no. 3, pp. 361-366, 1997. 